\title{
LA LIBRE CONTRATACIÓN FRENTE A LOS CAMBIOS LEGISLATIVOS
}

\author{
CONTRA LA SUPUESTA CONSAGRACIÓN CONSTITUCIONAL \\ DE LA SANTIDAD DE LOS CONTRATOS
}

RAFFO VELÁSQUEZ*

\section{Resumen}

Los recientes cambios legislativos que buscan menguar los efectos perjudiciales que la nueva realidad (pandemia) genera sobre los negocios jurídicos, ha levantado un viejo tópico que tiene que ver con el nivel de protección que debe reconocerse a los contratos frente a los cambios legislativos. La discusión sobre la supuesta santidad de los contratos tiene raíces históricas y constitucionales que deben ser bien entendidos para evitar tergiversaciones en el campo del derecho civil y sus tendencias actuales de abandonar la visión liberal para abrir campo a una visión más social de los contratos.

\section{Palabras Clave}

Retroactividad, contratos, derecho civil, derecho constitucional, jurisprudencia.

Artículo recibido para su evaluación el 1 de octubre de 2020, y aprobado para su publicación el 29 de diciembre de 2020

* Magíster en Argumentación Jurídica por la Universidad de Alicante y la Università degli studi di Palermo; Posgrado en Arbitraje Comercial Internacional por la Universidad Complutense de Madrid. Abogado por la Universidad Nacional Mayor de San Marcos. Socio de Baxel Consultores, en Lima - Perú. Emai: rvelasquez@baxel.pe. 


\begin{abstract}
The recent legislative changes that seek to lessen the harmful effects that the new reality (pandemic) generates on contracts, has raised an old topic that has to do with the level of protection that must be granted to contracts against legislative changes. The discussion on the alleged sanctity of contracts has historical and constitutional roots that must be well understood in order to avoid distortions in the field of civil law and its current tendencies to abandon the liberal vision to open the way to a more social vision of contracts.
\end{abstract}

\title{
Key Words
}

Retroactivity, contracts, civil law, constitutional law, jurisprudence

\section{INTRODUCCIÓN.}

La pandemia que azota al planeta nos fuerza a revisar los fundamentos de distintos institutos jurídicos que parecen insuficientes, defectuosos, inadecuados e incluso incomprendidos para afrontar el escenario actual. Uno de ellos es la libertad de contratar cuyos contenidos y alcances ahora más que nunca están en debate.

En varios países se discuten incumplimientos de contratos por alteración de las circunstancias, fuerza mayor, excesiva onerosidad $u$ otros supuestos generados por la pandemia que azota el planeta. A la par, se dictan o preparan paquetes legislativos que pretenden intervenir, muchas veces de manera desordenada o sin ninguna noción de las garantías constitucionales, sobre contratos de arrendamiento a personas en estado de riesgo que no pueden trabajar ni pagar el alquiler, sobre el pago de pensiones a los colegios que redujeron y cambiaron la forma de prestar sus servicios, al sobre el pago de préstamos bancarios o hipotecarios, e incluso sobre el incumplimiento de contratos de construcción y de concesión suscritos con el Estado ${ }^{1}$.

1 Aclarar estos temas es de suma trascendencia práctica, pues, por ejemplo, debido al estado de emergencia sanitaria que impide a los menores asistir a los colegios, el Poder Ejecutivo dictó el Decreto Legislativo $\mathrm{N}^{\circ} 1476$ que estableció ciertas reglas que inciden sobre los contratos previos suscritos entre los padres de familia y el colegio. Por su parte, el Congreso alegó la situación de pandemia que vivimos para dictar la Ley $\mathrm{N}^{\circ} 31018$ que regula ciertos aspectos de los contractos de concesión vial. Actualmente, se debaten otras nuevas leyes que regularían los pagos de contratos de crédito bancario, arrendamiento, colegios, entre otros. 
En forma trasversal a todos esos temas, algunos han rescatado el viejo tópico de la intangibilidad o santidad de los contratos, otros hablan de derechos adquiridos, y los vinculan con el principio de no retroactividad de la ley, para sostener que la nueva legislación no podría alterar situaciones jurídicas contractuales previamente pactadas.

En estas líneas buscaremos demostrar que la libertad de contratación no tutela derechos adquiridos, ni una pretendida santidad en los acuerdos privados. Esto es, que esa libertad constitucional no impide que las nuevas leyes intervengan sobre la autonomía privada, pero sí exige ciertos elementos de razonabilidad y limitaciones en dicha intervención.

Para verificar esto recurriremos a un análisis dogmático de la distinción entre relaciones contractuales y sus consecuencias jurídicas. Lo que nos evitará confusiones sobre la aplicación del principio de irretroactividad y brindará coherencia al diseño constitucional normativo y jurisprudencial peruano. En ese camino nos toparemos con algunos los malos entendimientos en la doctrina peruana, pero que evidenciarán la filosofía actúa que inspira la libertad de contratación.

Lamentablemente lidiamos con un problema que se reitera en distintos países, por lo que finalmente haremos un breve repaso del tratamiento constitucional chileno y colombiano que se ha dado al problema de las nuevas leyes frente a contratos previos. Lo que nos indicará que, con otros elementos, se persigue una filosofía similar sobre la libertad de contratación y sus límites.

\section{DELIMITACIÓN DEL PROBLEMA.}

El 103 de la Constitución peruana dispone que: "La ley, desde su entrada en vigencia, se aplica a las consecuencias de las relaciones y situaciones jurídicas existentes y no tiene fuerza ni efectos retroactivos; salvo, en ambos supuestos, en materia penal cuando favorece al reo". Mientras que el artículo 109 de la Constitución precisa que la vigencia surge "desde el día siguiente de su publicación en el diario oficial", salvo que dicha ley postergue se vigencia.

Estos textos recogen las mismas reglas que ya había fijado los artículos I y III el Título Preliminar del Código Civil de $1984^{2}$ y que consagran dos

2 Artículo I. "La ley se deroga sólo por otra ley. La derogación se produce por declaración expresa, por incompatibilidad entre la nueva ley y la anterior o cuando la materia de ésta es íntegramente regulada por aquélla". 
principios complementarios que regulan la transición o cambio de leyes en el tiempo. De un lado, está el principio de irretroactividad que, en términos generales, exige que la nueva ley mantenga inalterable las situaciones pasadas, salvo que se trate de una ley beneficiosa en materia sancionadora. De otro lado, se encuentra el principio de aplicación inmediata según el cual la nueva ley regulará aquello que encuentre desde su entrada en vigor hacia adelante.

Imaginemos que acabamos de conseguir el puesto de cartero. Si nos ponemos a pensar en las cartas dejadas en el buzón postal, recogidas e incluso entregadas al destinatario, sabremos que no tenemos nada que hacer con respecto de ellas. Pero si miramos a las cartas que fueron dejadas en el buzón postal, pero aún no son recogidas de ahí ni entregadas a sus destinatarios, entonces nuestra labor será inmediata, pues deberemos avocarnos a completar el proceso de entrega. Más aún, seremos responsables de las nuevas cartas que se dejan en los buzones postales. Algo similar pasa con los principios de irretroactividad y eficacia inmediata de las leyes. El primero exige mirar las situaciones y consecuencias pasadas ya consumadas, de tal manera que se mantengan inalterables; y el segundo exige avocarse a los eventos actuales (sean que se hayan originado antes o recién) pero que están aún pendientes, para que se sujeten o adecúen de inmediato a la nueva ley.

El asunto parecía meridianamente claro, sin embargo, el artículo 62 de la Constitución Política lo problematiza más al disponer lo siguiente:

Artículo 62.

"La libertad de contratar garantiza que las partes pueden pactar válidamente según las normas vigentes al tiempo del contrato. Los términos contractuales no pueden ser modificados por leyes u otras disposiciones de cualquier clase. Los conflictos derivados de la relación contractual sólo se solucionan en la vía arbitral o en la judicial, según los mecanismos de protección previstos en el contrato o contemplados en la ley.

Mediante contratos-ley, el Estado puede establecer garantías y otorgar seguridades. No pueden ser modificados legislativamente, sin perjuicio de la protección a que se refiere el párrafo precedente".

Artículo III. "La ley se aplica a las consecuencias de las relaciones y situaciones jurídicas existentes. No tiene fuerza ni efectos retroactivos, salvo las excepciones previstas en la Constitución Política del Perú". 
El debate gira alrededor de esta norma y tiene que ver con los efectos que tienen las nuevas leyes sobre los contratos previos, ya sea que hayan sido negociados entre las partes o que se trata de contratos modernos (por adhesión) en donde el poder de negociar se encuentra limitado, pues el mandato constitucional no distingue entre las modalidades contractuales que se sujetan a él.

La respuesta sobre la relación entre nuevas leyes y contratos previos parece sencilla, pero no lo es tanto. La regla es que lo pasado se debe regir por la ley antigua y lo nuevo por el régimen recién sancionado. El problema, como dice Fiore, es determinar con precisión qué debe considerarse como pasado respecto de la nueva ley ${ }^{3}$. Algunos postulan que los artículos 62 y 103 de la Constitución permite que las nuevas leyes incidan sobre contratos suscritos previamente pero que aún existen $\mathrm{y}$, en esa medida, no son pasados; otros dicen que esas mismas disposiciones permiten considerar a los contratos previos como parte de los eventos pasados y, por ende, objeto de una intangibilidad o santidad frente a las nuevas leyes. Y están los de la postura media, como nosotros, que sostienen que solo una parte del fenómeno contractual se rige por la ley antigua y otra por la nueva ley.

Para atender este problema, es conveniente acotar el escenario hipotético sobre el cual desarrollaremos nuestra evaluación:

1. Analizaremos situaciones intermedias, eventos surgidos bajo una ley antigua, pero que se prolongan en el tiempo de modo que durante su existencia surge una nueva ley. Los eventos consumados en su totalidad bajo una sola ley no serán objeto de análisis. Kemelmajer delimita así el asunto que queremos atender: "El problema aparece cuando un cambio legislativo se presenta durante la vida de hechos, relaciones o situaciones [jurídicas], o sea, entre que nacen y se extinguen. En tal caso, ese cambio legislativo trae aparejada una colisión o conflicto de normas en el tiempo y es necesario decidir qué norma ha de aplicarse ${ }^{4}$ ".

2. Asumiremos que estamos ante situaciones en donde no existe derecho transitorio que regule la manera en que interactúan la antigua y nueva ley como, por ejemplo, que establezca que los contratos previamente suscritos, sigan sujetando sus efectos a la ley antigua. Es decir, asumiremos que

3 FIORE, Pascuale: De la irretroactividad e interpretación de las leyes. $4^{\mathrm{a}}$ edición, Reus, Zaragoza, 2009. (Traducción de Enrique Aguilera de Paz). p. 19.

4 KEMELMAJER DE CARLUCCI, Aída: La aplicación del Código Civil y Comercial a las relaciones y situaciones jurídicas existentes. Rubinzal-Culzoni, Buenos Aires, 2015. p. 19 
estamos en una situación de ausencia de derecho transitorio específico, por lo que solo cabe recurrir a las reglas generales de temporalidad que prevén los artículos 62, 103 y 109 de la Constitución Política.

3. No haremos referencia a aquellos acuerdos que suponen que el Estado ha otorgado seguridades y garantías al inversionista, conocidos como contrato-ley. Tampoco nos referiremos al cambio de leyes que tengan que ver con la regulación de situaciones de derecho público, como normas sancionadoras, estado civil, entre otras.

4. El análisis recaerá en contratos suscritos de conformidad con el orden público y las leyes vigentes al momento de su suscripción, aunque se hará referencia específica a alguna jurisprudencia que proscribe contratos injustos o irrazonables.

5. Estas líneas se referirán a los cambios de leyes imperativas que deben cumplir las partes de un contrato. Aunque haremos algunas menciones a los cambios de leyes supletorias que las partes voluntariamente pueden integrar o no a sus contratos, el eje central del debate se vinculará con el cambio de leyes imperativas.

Dentro de esas circunstancias, estos son los problemas a ser atendidos: ¿qué relación tienen los contratos frente a nuevas leyes imperativas? ¿Son intangibles, o pueden ser afectados por la nueva ley? Y, de ser así ¿hasta qué punto puede llegar esa afectación?

\section{CONSTRUCCIÓN DOGMÁTICA DE LA PROPUESTA.}

\subsection{Relaciones, situaciones y consecuencias.}

El postulado que defendemos es que los artículos 62, 103 y 109 de la Constitución consagran lo que cierta doctrina española denomina "retroactividad en grado medio" de la nueva ley sobre los contratos previos. Para comprender dicho concepto es necesario recurrir a las ideas de Roubier, asumidas por la mayoría de la doctrina y por varias legislaciones (como la nuestra) que parten por distinguir entre situaciones jurídicas y sus consecuencias. (Roubier prefiere usar solo la frase "situaciones" pues abarca posiciones unilaterales y multilaterales. Sin embargo, aquí analizamos solo relaciones contractuales, por lo que usaremos de modo indistinto las palabras situaciones o relaciones jurídicas.)

Esa distinción ha sido muy útil en el derecho civil argentino cuyo antiguo artículo 3 del Código Civil y actual artículo 7 del Código Civil y Comercial tiene un tenor casi idéntico a nuestras normas civiles y constitucionales 
sobre derogación, al consagrar que: "A partir de su entrada en vigencia las leyes se aplican a las consecuencias de las relaciones y situaciones jurídicas existentes..." (énfasis agregado). La doctrina argentina que desarrolla las propuestas de Roubier pone énfasis en esta distinción entre situaciones o relaciones jurídicas, de un lado, y los efectos o consecuencias que aquéllas generan, de otro lado. Lo primero, no genera muchos problemas para nuestros propósitos porque el artículo 1351 del Código Civil define al contrato como el acuerdo de voluntades que da lugar a una relación jurídica patrimonial. Y dentro de los elementos de esa relación está el objeto, contenido o los términos pactados en las partes, que es lo que tiene una expresa protección constitucional.

Con respecto a las llamadas consecuencias de las situaciones o relaciones jurídicas, el profesor argentino Julio César Rivera explica que: "las consecuencias son todos los efectos -de hecho, o de derecho- que reconocen como causa una situación o relación jurídica existente... Las nuevas leyes se aplican se aplican a las consecuencias que se producen después de la sanción de la nueva ley. Así, si una ley reduce el monto de los alquileres urbanos en un $10 \%$, ella se aplicará a los cánones que se hagan exigibles con posterioridad a su entrada en vigencia. No se aplicará a los meses ya pagados, pues éstas son consecuencias ya producidas; ni a los meses pasados, aunque no hayan sido pagados". Esta será la noción abarcadora que usaremos.

\subsection{Propuesta de retroactividad media.}

Considerando los elementos anteriores, podemos evaluar los siguientes tipos de retroactividad que usan autores como De Castro ${ }^{6}$, Albaladejo ${ }^{7}$ y Diez-Picazo y Gullón ${ }^{8}$ :

1. Retroactividad en grado máximo o fuerte, que ocurre cuando la nueva ley se aplica a las relaciones jurídicas nacidas al amparo de

5 RIVERA, Julio César: Instituciones de derecho civil. Parte general. Tomo I. LexisNexis, Buenos Aires, 2004. pp. 225-226

6 DE CASTRO Y BRAVO, Federico: Derecho civil de España, Tomo I. Thomson-Civitas, Madrid, Reimpresión del 2008. pp. 648-649

7 ALBALADEJO, Manuel: Derecho Civil I - Introducción y parte general, 15 a edición, Librería Bosch, Barcelona. pp. 206-208.

8 DIEZ-PICAZO, Luis y GULLÓN, Antonio: Sistema de derecho civil, Volumen I, $13^{\text {a }}$ edición, Madrid, Tecnos. pp. 103-104. 
la ley anterior y a sus consecuencias, sean que se hayan consumado o aún no.

2. Retroactividad en grado medio, que se da cuando la nueva ley se aplica a los efectos pendientes de consumarse de las relaciones jurídicas. Si bien estas nacieron y consumaron parte de sus efectos bajo la anterior ley, aquellos que estuvieran pendientes de ejecutarse o desplegarse se sujetarán al nuevo régimen.

3. Retroactividad en grado mínimo o atenuada, que se produce cuando la nueva ley se aplica solo a los efectos que nacieran después de la vigencia del nuevo régimen, de modo que los efectos que surgieron y se prolongaron desde que regía la ley anterior se mantendrán bajo el amparo de ella.

Moisset de Espanes se muestra a favor de la retroactividad media, lo que significaría que la nueva ley actuaría de la siguiente manera: "Las relaciones o situaciones jurídicas nacen, se modifican o se extinguen en virtud de hechos a los cuales la ley reconoce eficiencia generadora. Esos hechos 'constitutivos'... serán regidos y juzgados por la ley vigente en el momento de producirse. Una vez formada la relación, el cambio de leyes no puede afectar su 'constitución'... Si las situaciones ya formadas continúan produciendo efectos, estas consecuencias serán juzgadas por la ley vigente al momento en que acaezcan; de tal manera que la nueva ley atrapa de inmediato los nuevos efectos, pero no los que se habían producido con anterioridad a su vigencia"'. En suma, conforme a la retroactividad media, será aplicación inmediata y no retroactiva de la nueva ley si se intervienen las consecuencias actuales de las relaciones contractuales previas.

\subsection{Derivaciones de la retroactividad media}

La retroactividad media permite deducir algunos postulados. Por ejemplo, que la nueva ley contravendría el principio de irretroactividad si rigiera situaciones jurídicas y sus consecuencias consumadas antes de su entrada en vigor. Sin embargo, en virtud del principio de aplicación inmediata, la nueva ley sí regirá la modificación o extinción de la situación jurídica contractual que se realice durante su periodo de vigencia, aunque la creación de tal situación haya sido previa. Asimismo, la nueva ley regirá

9 MOISSET DE ESPANES, Luis: Irretroactividad de la ley y el nuevo art. 3 del Código Civil. Universidad Nacional de Córdova, Córdova, 1976. pp. 41-42. 
a las consecuencias futuras de las situaciones jurídicas nacidas bajo la ley anterior, pero que aún siguen produciéndose.

Borda $^{10}$ y Kemelmajer ${ }^{11}$ abrazan también la propuesta de retroactividad media, de donde derivan las siguientes conclusiones:

(a) Las nuevas leyes que gobiernan la constitución, modificación o extinción de una relación o situación jurídica no pueden afectar eventos acaecidos bajo la ley antigua. Es decir, una nueva ley no puede afectar la constitución y modificación de un contrato realizada al amparo de la ley antigua. Por ejemplo, si una nueva ley exige como requisito de validez la existencia de una escritura pública para la constitución o modificación de los contratos de arrendamiento, tal ley no podrá alcanzar a los contratos de alquiler celebrados o prorrogados antes de la vigencia de dicha ley, lo mismo pasaría si dispusiera que las condonaciones de deudas que no se elevan a Escritura Pública no son válidas ${ }^{12}$.

(b) Las nuevas leyes que regulan la extinción de situaciones jurídicas no pueden afectar las situaciones ya extinguidas según las leyes antiguas. Por consiguiente, la ley nueva sí podrá afectar una relación jurídica no extinguida, en curso de acción. Por ejemplo, una nueva ley establece que el uso abusivo del derecho de usufructo es causal de extinción de ese contrato: (i) Será retroactiva si considera los abusos ocurridos antes de su vigencia, para extinguir el contrato; y, (ii) no lo será, si solo considera los

10 BORDA, Guillermo: Manual de derecho civil - Parte general. 18 a edición. Editorial Perrot, Buenos Aires, 1996. pp. 106-107.

11 KEMELMAJER, cit., pp. 34-36.

12 Usualmente la creación, modificación o extinción de situaciones o relaciones jurídicas nacen de hechos jurídicos que casi siempre se agotan en el momento mismo en que se producen. Si no se prolongan en el tiempo, se rigen por las leyes existentes al momento de su ocurrencia. Por eso, se suele poner énfasis en la distinción entre situaciones jurídicas y consecuencias que surgen de ellas, pues es más sencillo notar cómo éstas se prolongan en el tiempo y, por ende, cómo están expuestas a los avatares de los cambios de leyes.

Pero Moisset de Espanes (cit, pp. 23 y 41) advierte que puede ocurrir que el nacimiento de situaciones jurídicas no provenga de hechos jurídicos de constitución inmediata, sino que requieren de un periodo de gestación durante el cual puede ocurrir que las leyes que regulaban la constitución de situaciones jurídicas sean modificadas. En tal caso, resalta, la constitución misma de la situación deberá ser juzgada según la ley vigente al momento en que se completó el proceso de gestación, pues dicha constitución aún no se había consumado. En contrapartida, si según la ley antigua ciertos hechos no llegaron a constituir una relación o situación porque les faltaba algún elemento, tales hechos no llegarán revivir y a constituir tal relación, aunque la nueva ley no exigiera el elemento que faltaba antes, pues eso significaría darle un efecto retroactiva a la ley nueva. 
abusos acaecidos desde la vigencia de la nueva ley, aunque el contrato se constituyera bajo la antigua ley.

(c) Las nuevas leyes no pueden afectar las consecuencias consumadas bajo las leyes antiguas. El nuevo régimen sólo podrá alcanzar a las consecuencias que se encuentran en curso de realización desde la entrada en vigor de la nueva ley. Por ejemplo, sería ilegítima una nueva ley que reduce la tasa de interés legal y dispone que el excedente cobrado anteriormente por intereses deba ser devuelto.

Siguiendo a Moisset de Espanes podemos decir que las obligaciones contractuales dan lugar a la constitución de distintas situaciones jurídicas. De modo que, si existe una obligación de reparar, ésta se sujetará a las reglas de la ley vigente al momento de esa constitución. Pero, si el responsable no cumple con indemnizar, esa situación tendrá como consecuencia el devengar nuevos intereses, y si en ese interín, surge una nueva ley que varía el tipo de interés legal, a partir de su vigencia se calcularán los intereses según el nuevo régimen, pues se trata de consecuencias no consumadas bajo la ley anterior, sino ocurridos al amparo de la nueva ley ${ }^{13}$.

\subsection{Nuestra propuesta.}

La retroactividad media tiene muchas variables y tesis adicionales que pueden generar confusiones. Para evitar perdernos en una maraña de hipótesis y tesis, así como de los regímenes aplicables de retroactividad o aplicación inmediata, recurriremos al recuadro de Moisset de Espanes ${ }^{14}$ aunque con ciertas modificaciones que recogen los postulados que defenderemos al asumir la retroactividad media en los contratos.

Situaciones jurídicas de fuente contractual:

\begin{tabular}{|c|c|c|c|}
\hline \multirow{2}{*}{$\begin{array}{l}\text { Situaciones y efectos } \\
\text { jurídicos constituidos } \\
\text { y pendientes de fuente } \\
\text { contractual }\end{array}$} & \multirow{2}{*}{$\begin{array}{c}\text { Leyes } \\
\text { imperativas }\end{array}$} & $\begin{array}{l}\text { Situaciones: } \\
\text { a) Constitución o } \\
\text { modificación antes } \\
\text { b) Extinción posterior }\end{array}$ & $\begin{array}{l}\text { Rige ley antigua } \\
\text { (irretroactividad de } \\
\text { la nueva) } \\
\text { Rige ley nueva } \\
\text { (tiene efecto } \\
\text { inmediato) }\end{array}$ \\
\hline & & $\begin{array}{l}\text { Consecuencias: } \\
\text { a) Anteriores } \\
\text { b) Posteriores }\end{array}$ & $\begin{array}{l}\text { Rige ley antigua } \\
\text { (irretroactividad de } \\
\text { la nueva) } \\
\text { Rige ley nueva } \\
\text { (tiene efecto } \\
\text { inmediato) }\end{array}$ \\
\hline
\end{tabular}

13 MOISSET DE ESPANES, cit, p. 43.

14 Ibídem, p. 23. 
En otros términos, nuestra propuesta se sustenta en una distinción entre vigencia y eficacia de las leyes. Lo primero significa pertenencia al ordenamiento jurídico de un dispositivo y lo segundo regulación o gobierno efectivo de tal dispositivo sobre su objeto. Lo usual es que una norma vigente sea eficaz sobre las situaciones por ella regulada, sin embargo, como señala Diez-Picazo Giménez pueden darse casos que una norma sea ineficaz a pesar de no estar vigente o que la norma tenga vigencia, pero no eficacia. Y es que, según concluye, "nada impide que una ley que ha dejado de pertenecer al ordenamiento continúe surtiendo efectos durante algún tiempo, ni que una ley actualmente incardinada en el propio ordenamiento no despliegue efectos por un cierto periodo ${ }^{15}$ ".

Esta distinción es usada por el legislador peruano en la Segunda Disposición Final del Código Procesal Civil, que dispone que un proceso judicial iniciado bajo la "vigencia" de la regla $X$, seguirá rigiéndose por ella a pesar de que, durante su trámite, la regla $X$ sea derogada y sustituida por la regla $Y$. Es decir, estará "vigente" la regla $Y$ desde el día siguiente de su publicación, pero no será "eficaz" para los procesos iniciados antes de su "vigencia", sino que solo lo será para los nuevos procesos iniciados.

Nuestra propuesta es que la ley antigua sigue siendo eficaz con respecto a las situaciones, relaciones o consecuencias acaecidas durante su periodo de vigencia, mientras que, la nueva ley estará vigente, pero sin ser eficaz sobre aquellas, sino que desde su vigencia su eficacia solo recaería en las consecuencias actuales de esos acuerdos previos.

\section{5. ¿Santidad de los contratos?}

Como vemos, solo habrá intangibilidad (santidad para algunos) de los contratos con respecto a las situaciones de constitución o modificación de relaciones jurídicas (y, desde luego, de los contenidos que son objeto de ellas), puesto que, una vez establecidas, no podrá ser alterados por nuevas leyes. Cosa distinta pasa con sus consecuencias que sí serían alcanzadas por nuevas leyes, aunque la magnitud de esa intervención está por verse. Los defensores de la santidad de los contratos tendrían una oportunidad para decir que hay zonas son intangibles en los contratos, aunque deberán reconocer que es necesario contar con un bagaje de disgregaciones conceptuales para saber eso.

15 DIEZ-PICAZO GIMÉNEZ, Luis María: La derogación de las leyes. Civitas, Madrid, 1990. pp. 217-218. 
El problema con la llamada "santidad de los contratos" se genera por esta asimilación de cualidades humanas a un instituto jurídico, con el propósito de resaltar su indiscutible pureza o intangibilidad frente a intromisiones externas o mundanas. Este recurso figurativo genera una natural tendencia totalizadora que permite predicar la santidad de todo el fenómeno contractual, lo que no es exacto. Nuestra propuesta que distingue espacios protegidos y zonas pasibles de intervención estatal no admite el uso de la frase santidad de los contratos, pues es lingüística y figurativamente inadecuado sostener que una parte del fenómeno contractual es santo y otra parte no. La frase coloquial "santo, pero no tanto", sirve para las bromas, pero no para hacer dogmática jurídica. Para evitar esos y otros equívocos, es recomendable erradicar el uso de la tan reiterada santidad de los contratos ${ }^{16}$.

\section{CONSTRUCCIÓN JURÍDICA DE LA PROPUESTA.}

\subsection{Visión de los contratos en el artículo 62 de la Constitución.}

Para comprender la materialidad buscada con la consagración de libertad de contratar en el artículo 62 de la Constitución peruana puede ser útil hacer un recuento de las palabras de Carlos Torres y Torres Lara que formó parte del Congreso Constituyente que dictó la actual Carta Fundamental y que fue uno de los autores que postuló y fundamentó la redacción de la mencionada disposición. El profesor Carlos Cárdenas hace un recuento de algunos discursos del congresista constituyente que al final figuraron de modo resumido en el proyecto de Constitución publicado en "El Peruano" el 1 de julio de 1993. Citamos parte de uno de esos discursos:

"Hay otro concepto fundamental en este cambio. Es la visión sobre los contratos (art. 62). Se establece una nueva forma por la cual se prohíbe la dación de disposiciones legales que modifiquen los contratos, porque ha sido usual en el Perú, como en toda Latinoamérica, ese espíritu de justicia

16 Conthe señala que entre quienes se comunican se suele asumir que todo lo dicho es relevante, sin omitir elementos que alteren el significado del mensaje. De modo que, si se predica la santidad de los contratos, se da a entender que todo el contrato debe ser elevado a la condición de tótem intocable, obviando otros elementos que cambian o eliminan por completo el sentido de lo que se dijo. Esa confianza hace viable algunas bromas como la Groucho Marx que puede servir de ejemplo: "Desde que cogí tu libro no he parado de reírme... algún día espero leerlo". Lo mismo pasa aquí, es muy difícil decir que existe santidad de los contratos, a pesar de que se reconoce que no todo en ellos es santo. CONTHE, Manuel: Pensar con arte. Biblioteca Nueva, Madrid, 2014. pp. 249-250. 
generalizada, en donde un legislador un día piensa que los alquileres están muy altos, y entonces promueve una ley normando que los alquileres queden congelados, y, por supuesto, muchos aplauden, pero no piensan en aquella anciana que vive con los alquileres de esa casa... Esa justicia 'general' no es justicia. La nueva Constitución traslada esta función a donde debe estar, al Poder Judicial. Allí deben determinarse los excesos en los contratos, allí debe determinarse el equilibrio de la contratación en la relación uno a uno, y no por decisiones legislativas que a la larga resultan absolutamente demagógicas y paralizadoras de la economía, porque la economía de mercado se basa en la contratación, y si la contratación no es segura, no puede producirse lo que se llama estabilidad para que el capital interno permanezca en el Perú y el externo sea convocado al país ${ }^{17 \%}$.

No sabemos si de manera consciente o inconsciente, pero la propuesta del constituyente coincide con la visión liberal de los contratos de origen francés que conviene revisar. Así, a mediados del siglo XIX, Laurent comentaba la libertad de contratación del Code napoleónico, bajo el cual se consideraba que los contratos tenían fuerza de ley porque impedían que, bajo las invocaciones de la equidad o de justicia, los jueces los o parlamentarios permitan liberar a las partes de cumplir lo que libremente aceptaron ${ }^{18}$. Un siglo después, los hermanos Mazeud daban cuenta del mismo principio, ahora calificado como protección de los derechos adquiridos por la jurisprudencia que, se sustentaba en la equidad y justicia de los contratos, que reclaman que las nuevas leyes no perturben la economía de ellos y la equivalencia de las prestaciones, por lo que, concluían, que la nueva ley no podrá afectar los efectos futuros de los contratos previos ${ }^{19}$.

Ese fue el escenario en donde formó la llamada santidad de los contratos, entendida como inalterabilidad absoluta de los acuerdos pactados frente a las nuevas leyes, como si se tratara de derechos adquiridos que nada puede quitar, afectar o alterar, incluso si la nueva ley estuviera sustentada en razones legítimas. Sin embargo, esa visión absoluta viene perdiendo fuerza

17 Cita de CÁRDENAS QUIRÓS, Carlos: “Autonomía privada, contrato y Constitución”. En: Bullard, Alfredo y Fernández, Gastón (editores): Derecho civil patrimonial. Pontifica Universidad Católica del Perú, Lima, 1997, pp. 48-51.

18 LAURENT, Francois: Principios de derecho civil francés. Tomo XVI, Tribunal Superior de Justicia del Distrito Federal, México, el texto original francés es de 1860, pero la edición en español es de 2009. pp. 273-274.

19 MAZEAUD, Henry; MAZEAUD, León y MAZEAUD, Jean: Lecciones de derecho civil. Parte Primera, Tomo I, EJEA, Buenos Aires, 1959. (Traducción de Luis AlcaláZamora). pp. 242-243. 
en Francia desde la etapa de pre y postguerra. Así, Larroumet señala que ley y jurisprudencia han dado lugar a un intervencionismo económico del legislador por razones de orden público que permiten la aplicación de una nueva ley sobre los efectos todavía no producidos de contrato previos, e incluso la revisión de contratos en ejecución actual o la resolución por una de las partes ${ }^{20}$.

No se trata de un fenómeno aislado, pues refiriéndose al derecho europeo continental y del common law, Zimmermann y Whittaker señalan que esos sistemas jurídicos "se han distanciado o están en proceso de distanciarse del paradigma del contrato, que se enfoca casi exclusivamente en la autonomía de las partes" y, agregan, que hay "un incremento en el valor dado a la lealtad de las partes, a la protección de la confianza, a las exigencias de cooperación, la necesidad de considerar el interés de la otra parte o la justicia sustantiva del contrato 21 ", lo que reflejaría una nueva propuesta de contrato en donde la autonomía de la voluntad tienen una potencia menos exagerada.

Esto indica que el artículo 62 de la Constitución se inspira en una lejana teoría francesa de la santidad de los contratos que en la actualidad presenta grandes grietas ante la necesidad de intervención estatal. Podemos enfadarnos, cuestionar, hacer esfuerzos por re-interpretar el texto normativo, pero no podemos tener una ceguera voluntaria frente a una norma cuyo lenguaje y espíritu liberal nos fuerza a reconocer algo de intangibilidad en los contratos. Es el escenario con el que tenemos que convivir.

De hecho, el TC es consistente en señalar que "no sólo respecto a los términos contractuales que contenga el contrato-ley, sino, en general, para todo término contractual, éstos "no pueden ser modificados por leyes u otras disposiciones de cualquier clase'..." (STC 0005-2003-AI, fd. 35 y STC 0003-2004-AI, fd. 13), o, incluso, desde un punto de vista teleológico, ha señalado que "si el Estado interviniera las relaciones contractuales modificando sus términos a través de disposiciones normativas de carácter general -como efectivamente ocurrió en el Perú en décadas pasadas-, la libertad contractual podría quedar disminuida o, inclusive, vaciada por completo de contenido... el artículo 62 de la Constitución, sin embargo, se configura como una garantía idónea para remover ese riesgo asegurando

20 LARROUMET, Christian: Teoría general del contrato. Volumen I, Temis, Bogotá, 1999. (Traducción de Jorge Guerrero). p. 114.

21 ZIMMERMANN, Reinhard y WHITTAKER, Simon: Good Faith in European Contract Law, Cambridge University Press, 2000. p. 700. 
que sean las partes del contrato y no terceros ajenos a la relación jurídica en cuestión, quienes tengan la última palabra respecto a su contenido" (STC 0006-2012-AI, fd. 27), de modo que es innegable la protección que tienen los términos pactados en todos los contratos comerciales, civiles, laborales, entre otros.

\subsection{Visión no absoluta del artículo 62 de la Constitución .}

Para interpretar los alcances de una disposición es determinante el lenguaje que usa su texto (aunque eso no significa que solo el lenguaje positivo resuelve todos problemas que debe atender el Derecho). El problema de eso, como advierte Carrió, es que el lenguaje suele ser ambiguo, vago o de textura abierta, lo que hace bastante útil (pero no determinante) recurrir al pensamiento de los autores de los textos, pues permite reducir los niveles de incertidumbre que podría tener el lenguaje usado ${ }^{22}$.

En efecto, sabemos cuáles son las ideas que inspiraron el artículo 62 de la Constitución, pero debe notarse que el lenguaje de ese dispositivo no las acoge plenamente. Su texto sólo garantiza que "los términos contractuales", el contenido de los acuerdos, no puedan ser modificados por leyes u otras medidas, salvo que sea en la vía judicial o arbitral. Esto ratifica nuestra propuesta sobre la retroactividad media que consagra la intangibilidad de la constitución de las relaciones o situaciones jurídicas (creación, modificación o extinción), lo que implica la intangibilidad de los acuerdos que ellas contienen.

El artículo 62 de la Constitución no hace ninguna distinción entre la constitución de relaciones contractuales y sus consecuencias, sino que solo extiende protección a las primeras frente a nuevas leyes. Por tanto, no debemos darle más alcances a ese texto del que tiene, más aún si el artículo 103 de la Constitución sí hace esa distinción y dispone que las nuevas leyes "se aplica a las consecuencias de las relaciones y situaciones jurídicas existentes y no tiene fuerza ni efectos retroactivos". Es decir, sin tocar la garantía sobre los "términos contractuales" protegidos por el artículo 62 de la Constitución, el artículo 103 dispone que la nueva ley sí podrá incidir sobre las consecuencias actuales de tales acuerdos, sin que eso signifique una aplicación retroactiva de ella.

22 CARRIÓ, Genaro: Algunas palabras sobre las palabras de la ley. Abeledo-Perrot, Buenos Aires, 1971. pp. 17-29. 
Por tanto, existen mandatos expresos del constituyente, que justifican diferenciar entre el contenido de los contratos y sus consecuencias, pues uno $\mathrm{y}$ otro tienen una posición distinta frente a las nuevas leyes y que no es otra que la aplicación del criterio de retroactividad media. Esta lectura, además, supone una adecuada integración del sistema jurídico, pues la incidencia de las nuevas leyes sobre las consecuencias o efectos de contratos previamente suscritos, no solo lo exige el artículo 103 de la Constitución, sino también el artículo III del Título Preliminar del Código Civil.

Por eso, sorprende que los autores nacionales no recurran a la distinción entre relación jurídica y consecuencias, sino que se vean obligados a asumir que el artículo 62 de la Constitución protege a todo el fenómeno contractual y, por ende, que se vean forzados a argumentar en contra de la intangibilidad o de la llamada santidad de los términos contractual frente a las nuevas leyes.

Estos defectos se aprecian en el Oficio $\mathrm{N}^{\circ}$ 970-2013-MP-FN-OAJ en donde el Ministerio de Justicia informa en el Sistema Peruano de Información Jurídica-SPIJ que el artículo 1355 del Código Civil fue tácitamente derogado por el artículo 62 de la Constitución. La norma civil dispone que: "La ley, por consideraciones de interés social, público o ético puede imponer reglas o establecer limitaciones al contenido de los contratos". El texto podría mantener su validez si se entiende, en primer lugar, que la ley que establece tales limitaciones se aplica al contenido de los futuros contratos y/o, en segundo lugar, que esas limitaciones recaerían solo sobre las consecuencias actuales de los contratos ya suscritos ${ }^{23}$. De modo que, tal derogación tácita por oficio no puede tener ninguna eficacia. Leysser León también cuestiona esa supuesta derogación tácita de la norma civil y señala que su uso “... puede ser esencial si el Gobierno toma la

23 Manuel De la Puente resalta que la primera lectura que proponemos iría en contra del sentido histórico del artículo 1355 del Código, pues durante diseño siempre se pensó que las nuevas leyes también recayeran sobre los contratos ya suscritos, más aún si se tenía en cuenta que el artículo III del Título Preliminar del Código Civil habilitaba a la nueva ley a tener efectos inmediatos sobre las consecuencias de relaciones contractuales ya establecidas. DE LA PUENTE Y LAVALLE, Manuel: "La libertad de contratar". En: Themis-Revista de Derecho, $\mathrm{N}^{\circ} 33$, Lima. p. 9. Es acertado lo que señala el maestro, sin embargo, el texto del artículo 1355 deja espacio para la primera interpretación propuesta. Además, en línea con las disposiciones que cita, la segunda propuesta también tiene espacio pues el artículo III solo habilita a que la nueva ley intervenga en las consecuencias de las relaciones contractuales existentes. 
decisión, de una vez por todas, de contribuir a la prevención de las disputas que nacerán de la emergencia sanitaria ${ }^{24 "}$.

\subsection{Los criterios del TC sobre la intangibilidad de los contratos.}

El artículo 1 de la Ley Orgánica del TC lo reconoce como el órgano supremo de interpretación constitucional y, en esa línea, el artículo VI del Título Preliminar del Código Procesal Constitucional dispone que los jueces deben interpretar y aplicar el Derecho conforme a los criterios fijados por el TC. Si la jurisprudencia del TC entiende que los cambios de leyes solo pueden alterar los efectos de los contratos y no su previa constitución o modificación (y con ello, sus contenidos), entonces, ya no quedarán más dudas de que en nuestro sistema existen criterios vinculantes y finales que consagran la retroactividad en grado medio de las nuevas leyes frente a los contratos.

Aunque el análisis de las sentencias del TC y de los criterios vinculantes que surgen de ellas, es distinto al análisis de los textos normativos Si bien algunas sentencias del TC prevén interpretaciones o instrucciones precisas sobre los alcances que "deben" tener ciertas normas, ese proceder no ha ocurrido con el asunto que nos interesa. De modo que, es necesario recurrir a los hechos y criterios relevantes (explícitos e implícitos ${ }^{25}$ ) de cada caso

24 LEÓN HILARIO, Leysser: "COVID-19, crisis sanitaria y retos del Derecho Civil. Entre la fuerza vinculante y la adecuación de los pactos contractuales", entrevista publicada en Gaceta Civil \& Procesal Civil, № 82, Lima. p. 21.

25 Son enormes las diferencias entre el derecho inglés y el peruano, sin embargo, debido a la orfandad de criterios nacionales sobre la detección de los principios o ratio decidendi en las decisiones judiciales, es conveniente recurrir a ese sistema para confirmar que su detección en un caso no necesariamente está redactada en el mismo texto de las sentencias. Así, Cross y Harris señalan que: "La ratio decidendi de un caso es cualquier regla de Derecho que haya sido implícita o explícitamente considerada por el juez como necesaria para llegar a su conclusión, teniendo en cuenta la línea de razonamiento adoptada por dicho juez". CROSS, Rupert y HARRIS, J. W.: El precedente en el derecho inglés. Marcial Pons, Madrid, 2012. (Traducción de Angélica Pulido). p. 96. En el influyente trabajo de Goodhart se advertía desde hace mucho que "no es la regla de derecho establecida por el tribunal, o la regla enunciada... lo que necesariamente constituye el principio [ratio] del caso... puede que no se pronuncie una norma de derecho en la sentencia, o que la norma, cuando se mencione, sea demasiado amplia o demasiado estrecha". GOODHART, Arthur: "The Ratio Decidendi of a Case". En: Modern Law Review, $\mathrm{N}^{\circ} 22$, 1959. p. 118. Por lo que concluía que la determinación de la ratio decidendi se debe fundamentar en "los hechos tratados por el juez como materiales [relevantes] y su decisión basada en ellos", es decir, la conexión que permite ir de una al otro será el principio [ratio] aplicado al caso. GOODHART, Arthur: "Determining the Ratio Decidendi of a Case". En: Yale Law Journal, N 40, 1930. p. 182. 
a fin de detectar los principios (ratio decidendi) que condujeron a las decisiones que adoptó el TC sobre la manera en que deben engranarse los artículos 62 y 103 de la Constitución.

Uno de los casos más relevantes para nosotros tiene que ver con una nueva ley referida a los contratos de los trabajadores que había en los órganos de control de los distintos organismos estatales. Tal ley disponía que el personal que había ingresado mediante concurso público pase a formar parte de la Contraloría General de la República. Se disponía el cese y liquidación de sus contratos, beneficios laborales y derechos en la entidad en donde estaban y el inicio de nuevos contratos y regímenes laborales en la Contraloría. El TC sostuvo que no había afectación de la libertad de contratar sólo si la nueva ley era entendida de tal modo que se necesitaba del consentimiento del personal para el cambio del régimen laboral que tenían antes. Y consideró que tampoco existía tal agravio por el cambio de una entidad a otra porque el empleador seguía siendo el Estado, de modo que para ese traslado no se requería consentimiento del personal.

Al evaluar la articulación de los artículos 62 y 103 de la Constitución, el TC señaló que: “... los contratos se rigen por las normas vigentes en cada momento y no, ultractivamente, por las existentes al momento de su suscripción. Esa es la interpretación reiterada de este Tribunal Constitucional en su jurisprudencia (sentencias recaídas en los expedientes 00025-2007PI, 00008-2008-PI y 00020-2012-PI, entre otras)" (STC 0006-2012-AI, fd. 24). Si bien las sentencias que se mencionan solo se refieren a la aplicación inmediata de la ley y no a la forma cómo se articulan una nueva ley y los contratos previos, el texto transcrito sí deja en claro que las nuevas leyes rigen de inmediato a los contratos existentes. Aunque no precisa cómo es que opera esa eficacia de la nueva ley sobre los contratos.

Otro caso que vale la pena analizar es el del estudiante que ingresó a su segunda carrera universitaria bajo ciertas condiciones que, sin embargo, cambiaron al año siguiente cuando se le impusieron ciertas pensiones fijadas por una reciente norma del rectorado de la universidad. Ante el amparo del estudiante, el TC precisó que, efectivamente, la nueva norma podía alterar los efectos de la relación estudiantil que estaban en curso desde el momento que entró en vigor, pero no podía alterar las circunstancias anteriores (STC 0606-2004-AA, fds. 2-4), lo que nos va dando luces a favor de nuestra propuesta.

También cabe mencionar el caso de una nueva que ley que redujo las asignaciones, subsidios y compensaciones por tiempo de servicios fijados 
por otra ley imperativa previa y que se generaban como consecuencia de la suscripción de contractos laborales entre los profesores y el Estado. De la decisión del TC se deriva que estimó que la nueva ley no afectaba la libertad de contratar, pues no alteraba el contenido de los contratos, ni eliminaba las consecuencias previas que había tenido en relación con las asignaciones, subsidios y compensaciones (efectos) derivados de esos contratos. El criterio que subyace en este fallo es que la nueva ley sólo alteraba las consecuencias futuras de los contratos, lo que significa que en lo sucesivo se aplicaría los nuevos montos de tales conceptos laborales (STC 0025-2007-AI, fds. 69-77).

Un caso polémico que resolvió el TC nos advierte sobre la necesidad de tener mucha prudencia en la identificación de lo que hemos llamado "efectos consumados" de un contrato que no pueden ser alterados por nuevas leyes. Se trata de un concepto jurídico indeterminado que puede traer algunos los problemas que veremos ${ }^{26}$.

El caso se relacionaba con un contrato de compraventa e importación de vehículos usados cuando estaba vigente una ley que permitía importar esos bienes con menos de ocho años de antigüedad. Un par de semanas después se dictó una nueva ley norma que impedía comerciar esos vehículos. El TC declaró fundado el amparo de la empresa al estimar que se trataba de vehículos que ya habían sido embarcados al Perú, de modo que imponer el nuevo régimen supondría una aplicación retroactiva de la norma (STC 0325-2001-AA). Podría decirse que se protegieron los efectos consumados de esos contratos, en el entendido que la entrega de los bienes ya estaba en camino. Sin embargo, muchos años después el mismo caso llegó al TC porque se sostenían que aún quedaba pendiente la entrega de otros vehículos que llegaron del extranjero y que se encontraban en la Aduana peruana. El TC precisó que su mandato no protegía a nuevas entregas de vehículos, por lo que se pretendía desnaturalizar sus mandatos (STC 04622010-AA).

Es decir, el TC reconoció la validez del contrato de compraventa de vehículos usados celebrado bajo una regulación que consideraba legítimo

26 En el siguiente caso, era evidente que estábamos antes consecuencias consumadas de contratos que no podían ser modificadas por una nueva ley. Se trata de un contrato de adjudicación gratuita de un predio rústico con fines agrarios que hizo el Estado a favor del señor Salvatierra. Sin embargo, años después el adjudicatario vendió distintos lotes para desarrollo urbano. Luego se dictó una nueva ley que la reversión de la propiedad al Estado si el adjudicatario no cumplía con el fin para el cual se le transfirió el predio rústico. Al amparo de esa nueva ley, se dictaron actos administrativos contra el señor 
su comercio en el Perú; incluso se aseguró de que las consecuencias consumadas de ese acuerdo no se vean alterados por la nueva ley. Y, al final, se aseguró de que la nueva ley rija sobre las nuevas consecuencias que podría generar tal contrato, por lo que desestimó un pedido de desaduanaje de los nuevos vehículos que habían llegado para ser comercializados.

En contrapartida, el TC sí consideró como intervenciones inconstitucionales sobre la libertad de contratar aquellas nuevas normas que: (a) directamente disponían la extinción de la relación contractual (STC 0078-2004-AA, fd. 3); (b) establecían cambios a las condiciones pactadas en ciertos contratos laborales previos (STC 3128-2011-AA, fd. 22; STC 2825 2004-AA y STC 3155-2004-AA); (c) cambiaban el contenido y las partes del contrato (STC 0001-2001-AI); (d) o, de manera más reciente, aquella nueva ley que alteraba los términos de un contrato de concesión, pues de modo directo suspendía parte del contenido del contrato que permitía el cobro de peajes y prohibía la activación de otras partes del contrato que permitía activar el acuerdo de compensación por el impedimento de cobro (STC 0006-2020-AI, fds. 86-88).

De este recuento se deriva que el TC, a veces de manera evidente y otras no tanto, ha diferenciado entre la alteración directa de relaciones contractuales por parte de nuevas leyes, y la alteración sobre las consecuencias actuales de acuerdos previamente celebrados. De un lado, ha estimado inconstitucional, por retroactiva, que una nueva ley invalide, suspenda o cambie los términos de un contrato previamente suscrito (STC 0078-2004-AA, fd. 3; STC 31282011-AA, fd. 22 y STC 0006-2020-AI, fds. 86-88) e, incluso, consideró inconstitucional que la nueva ley impida la inevitable consumación de las consecuencias de un contrato previo (STC 0325-2001-AA y STC 04622010-AA). De otro lado, el TC ha considerado constitucional por tratarse de un supuesto de aplicación inmediata, que una nueva ley incida solo sobre los efectos o consecuencias actuales de contratos anteriormente suscritos (STC 0606-2004-AA y STC 0025-2007-AI).

\footnotetext{
Salvatierra que dispusieron la reversión de la propiedad al Estado por no cumplir con el fin agrario. Al respecto, el TC declaró fundada la demanda de amparo contra esas medidas de reversión al entender que se trataba de una aplicación retroactiva de la nueva ley. Precisó que: "la transferencia de parte del predio rústico con fines urbanos no se encontraba proscrita ni por la Constitución ni la ley vigente en ese momento, por lo que mal puede invocarse la aplicación de una Ley posteriormente expedida... para disponer consecuencias jurídicas a actos de compraventa realizados con anterioridad a su entrada en vigencia" (STC 0958-2015-AA, fd. 20).
} 
Lo anterior indica que nuestra propuesta se corresponde con los datos constitucionales que existen sobre la relación que se genera entre los contratos ya celebrados y las nuevas leyes que podrían incidir sobre las consecuencias que ellos generan ${ }^{27}$.

\section{REPASO DE OTRAS PROPUESTAS NACIONALES.}

\subsection{La teoría de los derechos adquiridos.}

La llamada teoría de los derechos adquiridos permitiría mantener la existencia y eficacia de un derecho obtenido al amparo de un contrato previo, frente a cambios legislativos posteriores que pudieran afectarlos. Actualmente es una noción innecesaria para explicar los alcances de los artículos 62, 103 y 109 de la Constitución y, además, es una fuente generadora de confusiones, pero es conveniente recordar esta noción para evaluar las propuestas que recurren a su uso para interpretar la normativa constitucional ${ }^{28}$.

Los rezagos de esa teoría se deben a que el texto original del artículo 103 de la Constitución peruana no impedía que los derechos surgidos al amparo de una ley antigua tengan efectos ultraactivos, esto es, prolonguen su eficacia hasta después de que dicha ley quede derogada y sea sustituida por una nueva. Y es que antes el artículo 103 solo disponía que "ninguna ley tiene fuerza ni efecto retroactivo", mientras que ahora ese dispositivo prevé que desde la vigencia de la ley "se aplica a las consecuencias de las relaciones y situaciones jurídicas existentes y no tiene fuerza ni efecto retroactivo". Es decir, además de exigir que la nueva ley no sea retroactiva, el actual texto constitucional impone que la ley surta efectos ya, de

27 Mientras escribíamos estas líneas, el TC convalidó la constitucionalidad de una ley que modifico (extendió) los plazos de prescripción que aún no vencían y que eran aplicables a las deudas tributarias (STC 0004-2019-AI). Lamentablemente, el TC tuvo serios problemas en identificar las diferencias entre situaciones consumadas y sus consecuencias, lo que generó distintos votos en discordias y fundamentos de voto de los magistrados que suman a la confusión. Nos permitimos referir este breve comentario al fallo: VELÁSQUEZ, Raffo: "La grave confusión sobre el mandato constitucional de irretroactividad. Comentarios a la STC Exp. No 00004-2019-AI/TC”. En: Gaceta Constitucional. Tomo 154, 2020. pp. 139-160.

28 Se trata de nociones que arrastra desde hace mucho nuestro Derecho y que encuentra resonancia en la jurisprudencia civil. Así, la Corte Suprema señala que: “... el problema de la aplicación de las normas en el tiempo pone en discusión el tema de la seguridad jurídica y la innovación legislativa, por lo que para solucionar las mismas hay varias teorías, entre las que destacan: a) la teoría de los derechos adquiridos, que propugna que la norma bajo la cual nació el derecho, continúa rigiéndolo mientras tal derecho surta efectos, aunque en el trayecto la aludida [norma] 
inmediato, lo que no deja espacio a que se prolonguen las consecuencias de las situaciones nacidas bajo la anterior ley.

A su vez, el texto original de la Primera Disposición Final y Transitoria de la Constitución también reconocía expresamente la inalterabilidad de los derechos adquiridos por los pensionistas de los regímenes de los Decretos Leyes 19990 y 20530, es decir, aunque fueran derogadas esas normas, los pensionistas que lograron sujetarse a ellas, mantendrían ese tratamiento legal. Incluso, en la sentencia del 28 de febrero de 2003, caso Cinco pensionistas contra Perú, la Corte Interamericana invocó el anterior texto del artículo 103 de la Constitucional para condenar al Estado peruano por aplicar un régimen distinto a los reclamantes que habían adquirido sus derechos de pensión al amparo de los Decretos Leyes 19990 y 20530. Esa situación fue la que motivó la modificación constitucional que dispuso el cierre definitivo de aquel régimen pensionario y la modificación del artículo 103.

El TC ha ratificado la legitimidad de ambas modificaciones del texto constitucional (STC 0050-2004-AI y otros acumulados), lo que implica la erradicación definitiva de todo rezago de una teoría de los derechos adquiridos en nuestro actual sistema constitucional.

\subsection{Principales propuestas.}

Como indicamos nuestra doctrina no suele distinguir entre el reconocimiento de la inalterabilidad de los términos contractuales y la alterabilidad inmediata de los efectos o consecuencias actuales de los contratos por nuevas leyes, lo que ha generado que cuestionen la lectura textual del artículo 62 de la Constitución que, a su juicio, consagraría la santidad de los contratos o la teoría de los derechos adquiridos. Si bien hay varios comentarios relevantes del artículo 62 Constitución y/o de la

sea derogada o sustituida; y b) la teoría de los hechos cumplidos, la cual prefiere la aplicación inmediata de las normas antes la ultraactividad [prolongación] de la norma [que fue] derogada". Incluso la Corte Suprema señala que el artículo 62 de la Constitución recoge una "clara aplicación de la teoría de los derechos adquiridos", es decir, dispondría que el régimen jurídico bajo el cual se celebró un contrato se prolongue en el tiempo más allá de su derogación. POZO, Julio: Summa Civil. Nomos \& Tesis, Lima, 2018. pp. 35-36. 
supuesta santidad de los contratos que éste consagraría ${ }^{29}$, Carlos Cárdenas $^{30}$, César Landa y Fort Ninamancco son los autores que hacen propuestas específicas de interpretación de aquel dispositivo, por lo que el análisis de sus posiciones es sumamente útil.

Carlos Cárdenas ${ }^{31}$ señala que existe el peligro de aplicar una teoría de derechos adquiridos que consagre una santidad de los contratos de tal nivel que el legislador deba renunciar a que sus normas imperativas o de orden público afecten esos acuerdos privados. Eso, agrega, significaría crear una inmutabilidad de todo contrato civil o comercial que no lo haría distinguible de los contratos-ley, e incluso daría una protección similar sin necesidad de seguir el procedimiento que estos imponen, lo que sería absurdo. Por eso, propone que la santidad de los contratos solo sea predicable con respecto a las nuevas leyes que tienen carácter supletorio y no respecto de nuevas leyes imperativas. Aunque confiesa que esa interpretación iría en contra del texto del artículo 62 de la Constitución que se oponen a toda modificación proveniente de "leyes u otras disposiciones de cualquier clase". En todo caso, concluye, su propuesta serviría para corregir "el exceso verbal de la norma, atribuyéndole alcances menos amplios de los que supuestamente le corresponden".

El problema de esta propuesta interpretativa no es solo que va en contra del texto expreso, o del "exceso verbal" de una norma, sino que además supone aceptar que, para todos los casos, una parte de la Constitución deberá perder la fuerza que su texto consagra, posibilidad que proscribe el mismo

29 Marcial Rubio y Manuel De la Puente se resignan a asumir que el artículo 62 de la Constitución consagra la teoría de los derechos adquiridos o de la santidad de los contratos, respectivamente. Si bien ambos expresan una crítica a dicha opción, a diferencia de Carlos Cárdenas y César Landa, no proponen una interpretación que permite superar los cuestionamientos que formulan. Marcial Rubio sostiene que la norma en cuestión instaura un régimen arcaico e incoherente con las demás normas del sistema jurídico que prevén la teoría de los hechos cumplidos. Manuel De la Puente señala que aquella norma reconocería una santidad en los contratos que, de un lado, congelaría cada contrato bajo la ley que fue creada y, de otro lado, lo haría inmutable frente a nuevas leyes. De modo que, concluye, el Estado se vería forzado a ser infalible, ya que no tendría espacio para corregir las injusticias que generó a través de leyes previas que dieron lugar a contratos, motivo por el cual se confiesa "partidario de un intervencionismo estatal sensible y prudente" que permita alcanzar algo en la "socialización del contrato".

30 La propuesta del profesor Cárdenas es la que más aceptación ha tenido en la doctrina, pues es seguida por autores como César Ochoa y Baldo Kresalja, Walter Gutiérrez, Juan Espinoza, entre otros.

31 CÁRDENAS, cit., pp. 54-58; y del mismo autor: "La supuesta santidad de los contratos y el artículo 62 de la Constitución Política del Perú”. En: Gaceta Jurídica, Tomo 73-B, Lima, 1999. pp. 32-36. 
TC al señalar que el principio de fuerza normativa de la Constitución exige "respetar la naturaleza de la Constitución como norma jurídica, vinculante ‘in toto' y no sólo parcialmente" (STC 5854-2005-AA, fd. 12).

El otro problema es que no llega a advertir que los contratos pueden verse influenciados por nuevas leyes imperativas, sin necesidad de que eso signifique alterar sus contenidos o términos. De hecho, vimos que el TC, expresamente proscribe la posibilidad de que nuevas leyes imperativas alteren de forma directa el contenido de los contratos, lo que contradice la propuesta del autor. Esas nuevas normas podrán lograr su cometido de imponer sus condiciones sobre los contratos, alterando en mayor o menor medidas los efectos actuales que tienen. Lo que podrá forzar modificaciones de contratos para adecuar sus intereses económicos al nuevo régimen, o generar supuestos de extinción del contrato y/o desencuentros entre las partes que den lugar a controversias solucionables por jueces o árbitros.

Ninamancco, en una crítica que compartimos, cuestiona lo siguiente de esta propuesta: “... el artículo 62 de la Constitución no puede referirse a normas que no sean imperativas, ya que las normas dispositivas y supletorias no tienen que ver con los límites a la autonomía privada. De manera que, si se ensaya una interpretación restrictiva del artículo 62, en el sentido de que se refiere únicamente a normas dispositivas y supletorias, este perdería prácticamente todo su sentido práctico. Y una interpretación que conduce a vaciar el significado práctico de un precepto constitucional no parece oportuna ${ }^{32}$ ".

De manera más reciente, César Landa también sostiene que el texto del artículo 62 de la Constitución consagraría una excepción a la regla de la teoría de los hechos cumplidos, pues consagraría la teoría de los derechos adquiridos que supondría que los contratos (en general) no podrían ser modificados por normas posteriores. Sin embargo, precisa, el artículo 103 de la Constitución que recoge la teoría de los hechos cumplidos sería la norma-principio que inspira a toda la Constitución, mientras que el artículo 62 sería una norma-regla, lo que supondría que "la interpretación de esta última debe hacerse conforme al principio de los hechos cumplidos". Sobre todo, finaliza, cuando "el objeto del contrato o determinadas disposiciones son o se convierten en contrarias al orden público constitucional, sería posible objetarlas a través de una nueva norma legal, siempre y cuando

32 NINAMANCCO CÓRDOVA, Fort: La invalidez y la ineficacia del negocio jurídico en la jurisprudencia de la Corte Suprema. Gaceta Jurídica, Lima, 2014. p. 148. 
ella responda a los criterios de razonabilidad y proporcionalidad en la aplicación de la doctrina de los hechos cumplidos ${ }^{33}$ ".

La cuestión es que esta postura no logra a explicar el fundamento que la sostiene. Lo primero es que no se entiende por qué atribuye al artículo 62 la calidad de norma-regla y al artículo 103 la de norma-principio. Desde hace mucho el TC reconoce que el sistema jurídico está compuesto por normas-regla y normas-principio (STC 0008-2003-AI, fd. 4; STC 00062003-AI, fd. 8; STC 1417-2005-AA, fd. 11; RTC 0013-2006-AI, fd. 6...). En términos generales, las primeras describen una conducta específica y cerrada a ser realizada, de modo que exigen un cumplimiento exacto y pleno, como "prohibido el ingreso de perros al restaurant"; mientras que las segundas describen estados valiosos a ser alcanzados, por lo que no estatuyen una conducta específica y cerrada, aunque mediatamente ordenan acciones para alcanzar el fin perseguido en la mayor medida posible, como la norma "el restaurant brinda un ambiente agradable a sus clientes". La simple lectura de las disposiciones en comentario indica que ambas tienen la condición de normas-regla, de mandatos específicos y precisos, y no de la consagración de estados valiosos que se busca alcanzar. En efecto, una norma puede ser retroactiva o no, puede tener efectos inmediatos sobre consecuencias actuales o no. No hay espacio para ponderar la cualidades retroactivas o inmediatas de las leyes, tal como sugiere la propuesta del profesor Landa.

El segundo punto que no se aclara es, cómo así la interpretación según el test de proporcionalidad puede llevar a conclusiones que apunten en sentido contrario a la teoría de los derechos adquiridos que, según el autor, consagra el artículo 62 de la Constitución. Desde luego que, la interpretación constitucional puede servir para modelar, extender o limitar (hacer supra-inclusivo o infra-inclusivo, en términos de Schauer ${ }^{34}$ ) los alcances lingüísticos de las disposiciones en virtud de los principios que subyacen a ellas, pero en ningún caso tal esfuerzo interpretativo puede tener como fruto el sostener que un dispositivo dice algo totalmente opuesto a lo que su texto consagra. Es contradictorio reconocer que el artículo 62 de la Constitución consagra la teoría de los derechos adquiridos y, acto

33 LANDA ARROYO, César: "La constitucionalización del derecho civil: el derecho fundamental a la libertad contractual, sus alcances y sus límites". En: Themis-Revista de Derecho, $\mathrm{N}^{\circ}$ 66, Lima, 2014. p. 325.

34 SCHAUER, Frederick: Las reglas en juego. Un examen filosófico de la toma de decisiones basada en reglas en el derecho y en la vida cotidiana. Marcial Pons, Madrid, 2004. (Traducción de Claudina Orunesu y Jorge L. Rodríguez). pp. 89-92. 
seguido, señalar que la interpretación constitucional permitiría sostener que el supuesto que regula esa misma norma sería la tesis contraria, la de los hechos cumplidos.

Finalmente, Fort Ninamancco sostiene que debe darse una interpretación restrictiva del artículo 62 de la Constitución de modo que se entienda que el mandato es que otras normas "con fuerza de ley", como decretos de urgencia, decretos legislativos, ordenanzas y cualquier otra medida estatal de inferior rango, no puedan modificar los términos contractuales. Sin embargo, sostiene, la modificación de los acuerdos sí podría ser realizada mediante leyes propiamente dichas, emanadas del Congreso, pues, según concluye, es coherente con la forma en que el constituyente permite la intervención de la propiedad que, además, comparte la naturaleza constitucional y patrimonial de la libertad de contratar ${ }^{35}$.

Se trata, sin duda, de una propuesta novedosa que es coherente con las nociones constitucionales de intervención sobre los derechos. Y es que el artículo 2, numeral 24, literal a, de la Constitución y reiterada jurisprudencia del TC, resaltan que la intervención sobre los derechos constitucionales exige de leyes del Parlamento (de nuestros representantes) para ser legítima. Coincidimos en que es necesario dar una lectura restrictiva del artículo 62 de la Constitución, pero diferimos del camino elegido por el autor para materializar tal lectura. Y es que esa propuesta no logra superar el hecho que el texto del citado artículo 62 consagra la protección de los términos contractuales contra modificaciones que provengan de "leyes" y, si hay dudas de qué quiere decir eso, el constituyente extiende esa protección contra "disposiciones de cualquier clase" lo que, obviamente, incluye a las leyes del Congreso. De hecho, el mismo TC se ha encargado de señalar que aquel mandato constitucional "establece un límite a la potestad normativa del Estado, en virtud del cual la ley -y, eventualmente, otras fuentes formales de derecho- no pueden utilizarse para modificar el contenido de un contrato" (STC 0006-2012-AI, fd. 23 y en el mismo sentido la STC 48012017-AA, fd. 19), lo que nos obliga a descartar la propuesta analizada.

\section{CONSTRUCCIÓN COMPARADA DE LA PROPUESTA.}

Para culminar esta exposición debemos evaluar por qué debemos confiar en una visión dividida de la libertad de contratación. Es decir, por qué debemos convivir con un mandato que protege a los términos contractuales

35 NINAMANCCO, cit., pp. 157-159. 
frente a toda nueva ley y también aceptar otro mandato que no otorga la misma protección a las consecuencias de esos mismos contratos frente a las nuevas leyes, sino que acepta que estas sean sometidas al nuevo régimen jurídico.

\subsection{Nueva visión de los contratos.}

Es necesario remarcar que todos los planteamientos de nuestra doctrina expresan una legitima preocupación y, con ello, una dura crítica contra la aparente santidad absoluta de los contratos que consagraría nuestra Constitución. El propósito aquí no es impedir las defensas que se hacen desde la filosofía que debe inspirar a los contratos y que exigirían la intervención del legislador cuando se requiera la humanización de sus alcances o la socialización de sus contenidos. Solo hemos querido resaltar el único camino constitucional existente para que el legislador intervenga sobre los contratos.

Las palabras de Torres y Torres Lara efectivamente inspiraron el sentido del artículo 62 de la Constitución, a tal punto de que son ineludibles las protecciones que su texto consagra a favor de la inalterabilidad de los términos pactados en un contrato. Las preocupaciones del constituyente parecían ser las mismas que las del legislador y juez francés que hace algunas décadas enarbolaban la bandera de la libertad para evitar toda injerencia del legislador sobre los contratos.

Hattenhauer $^{36}$ y Roppo $^{37}$ recuerdan que las protecciones de inalterabilidad de los contratos tenían una fuerte inspiración liberal que veía a los contratos como un intercambio voluntario de porciones de libertades, lo que les permitía obrar como querían en ese ámbito, de modo que la intervención del poder público en esos ámbitos suponía una afectación de la libertad misma. Sin embargo, agregan, la realidad de la postguerra evidenciaría al mundo que estaban solo ante una igualdad formal, pues la libertad otorgada por la autonomía privada no sería suficiente para evitar ser aplastados por contrapartes con mayor poder o, en general, para impedir los abusos contractuales relacionados con la escasez, la vivienda o el trabajo ${ }^{38}$.

36 HATTENHAUER, Hans: Conceptos fundamentales de derecho civil. Ariel, Barcelona, 1987. (Traducción de Gonzalo Hernández). pp. 69-74.

37 ROPPO, Vicenzo: El contrato. Gaceta Jurídica. Lima, 2009. pp. 67-68.

38 En similar sentido se pronuncia el profesor colombiano Fernando Hinestrosa al señalar que: 
Por esos motivos, hace poco Manuel De la Puente nos enseñaba sobre la necesidad de socializar el contrato y Carlos Cárdenas de humanizar su regulación (y con ello, permitir la intervención estatal por motivos justificados). Ahora el fenómeno es incluso mayor, pues Cesar Landa hace referencia a la inevitable constitucionalización del derecho civil.

De hecho, el TC no ha sido ajeno al asunto, pues ha resaltado que, si bien la Constitución manda proteger la libertad de contratar, ésta no otorga garantías frente a "cláusulas irrazonables que terminen anulando un sentido mínimo de justicia y el sentido común" (STC 6534-2006-AA, fd. 3) y de manera aún más clara, estableció que: "la idealización o generalización de una sociedad donde las personas intercambian libremente bienes jurídicos y materiales, y donde los compromisos contractuales a los cuales se sujetan son adoptados en pleno ejercicio de su autonomía, constituye hoy en día y, a la luz de una larga experiencia histórica, una postura desencajada de la realidad y que, más bien, puede ocultar un sistema injusto de relaciones donde la persona más débil puede sucumbir en sus derechos e intereses ante el más fuerte" (STC 0228-2009-AA, fd. 24).

"El derecho civil, sobre todo el de la codificación, permitió la liberación de la persona, que se saliera del status, para regirse en adelante, según su iniciativa, por contrato, con vínculos ciertamente transitorios. Libertad de disposición, el contrato considerado kantianamente- como el summum de la igualdad y la justicia; consideración de que todas las personas (y la generalización de las personas individuales o físicas fue total, con olvido o relegación de las personas colectivas o jurídicas y de su gran poder económico y político perdurable) son iguales ante la ley y han de recibir del Estado el mismo trato.

Sin embargo, de ahí se ha pasado a considerar la libertad como algo dinámico, que no está dado de una vez para siempre y que, por el contrario, sufre amenazas continuas y cada quien debe esforzarse por conseguirla todos los días, asistido por el Estado con esa finalidad. Libertad de uno que no puede excluir la de otro y que puede verse mermada, para que ese otro pueda ejercitar la suya. Restricciones y exigencias positivas sobre la autonomía individual, de modo de mejorar las condiciones de vida de quienes se encuentran en las esferas sociales deprimidas. Intervención del Estado para asegurar y acelerar dicho proceso.

Reconocimiento del dato exacto de que, lejos de haber igualdad, lo que impera es la desigualdad, y de que si se aspira a un equilibrio social es menester defender, apoyar, estimular a quienes, por razones de diversa índole, pero especialmente económicas y culturales, se encuentran en desventaja para la disposición de sus intereses frente a los demás y en concurso con ellos. Tutela que va de la erección de ramas singulares del derecho en adelante101, y que no solamente tiende a proteger a los individuos y comunidades económicamente débiles, sino también a quienes, a despecho de su caudal patrimonial, se encuentran dentro de una masa dispersa y con pocas posibilidades de defensa aislada, como sería la de los consumidores o usuarios". HINESTROSA, Fernando: "Función, límites y cargas de la autonomía privada". En: Revista de Derecho Privado, $\mathrm{N}^{\circ} 26$, Universidad Externado de Colombia, Bogotá, 2014. p. 38. 
Esta nueva visión del contrato es una reivindicación de la teoría constitucional sobre las relaciones privadas y exige racionalizar la noción de libertades que nunca pueden ser entendidas en forma absoluta, sino que siempre cabe su delimitación debido a la exigencia de otros principios o valores constitucionales que así lo exigen en ciertas circunstancias. En todo caso, para la doctrina y jurisprudencia nacional y comparada, no es nuevo decir que todo derecho o libertad es pasible de delimitación.

\subsection{Ponderar la nueva y antigua visión de los contratos.}

Así como la doctrina ha cuestionado la manera terminante en que el artículo 62 de la Constitución impone la visión liberal de los contratos, sin un aparente margen de maniobra para ponderaciones, tampoco podemos aceptar que el artículo 103 de la Constitución sea usado para imponer nueva visión social o interventora absoluta en los contratos. Por tanto, esta última también debe ser pasible de al menos dos reparos que se deben tenerse siempre presente al momento de su aplicación.

Esta nueva visión de los contratos tiene un camino constitucional que permite al legislador intervenir sobre las injusticias de los contratos, sobre las consecuencias actuales de tales acuerdos. Sin embargo, el hecho de que nuevas leyes puedan intervenir sobre tales consecuencias no significa que el orden constitucional admita todo tipo de intervención legislativa. Además de respetar el artículo 103 de la Constitución, al orden constitucional le interesa que las nuevas leyes respeten las demás normas y garantías del orden constitucional. Por tanto, el hecho que una nueva ley cumpla con la exigencia de retroactividad media no significa que su contenido esté exonerado de cumplir otros criterios de razonabilidad y legitimidad constitucional ${ }^{39}$.

También debe tenerse en cuenta que la retroactividad media permite, al final de cuentas, intervenir posteriormente sobre elementos que proviene de contratos previamente suscritos, aunque sea solo sobre las consecuencias

39 Por ejemplo, en el proceso de inconstitucionalidad contra la nueva ley que prohibía la contratación estatal para fines publicitarios, era manifiesto que no se vulneraba la garantía de irretroactividad, pues no recaía sobre contratos ya suscritos. Sin embargo, el TC consideró que tal ley era inconstitucional porque afectaba otras garantías, como la libertad de información (STC 0012 y 0013-2018-AI). De manera similar, ante una nueva ley que pretendía instaurar cambios en el personal contratado de control institucional, el TC precisó que tales reformas serían legítimas si tenían "por objeto perfeccionar objetivos constitucionalmente valiosos" (STC 0006-2012-AI, fd. 28). 
de estos, de modo que no puede ser pensado como un remedio usual de intervención estatal. Es necesario ser prudente en su uso, y dar una lectura restrictiva de dicha potestad. Si una nueva ley va a intervenir con bastante fuerza sobre las consecuencias de contratos previos, incluso al punto de hacerlas impracticables o ineficaces, debe existir una justificación real y objetiva que legitime tal medida. En ese sentido, Lon Fuller recuerda que cuando las cosas andan mal es cuando se podría justificar recurrir a leyes con cierta retroactividad, como una medida correctiva. Pero, agrega, eso no debe hacernos olvidar que la regla debe ser que la ley apunte hacia el futuro, pues "hablar de gobierno [de la conducta] o dirigir la conducta hoy a través de reglas que se promulgarán mañana es hablar por hablar ${ }^{40}$ ". En igual sentido, Fiore resalta que la irretroactividad es el principio reconocido que "no niega el poder que tiene el mismo legislador de dar efecto retroactivo a ciertas disposiciones, por más que tal poder debe usarse en circunstancias muy excepcionales y por motivos de interés público, y con las limitaciones que la equidad requiera ${ }^{41}$ ".

La nueva visión social de los contratos convivirá en constante interacción y delimitación con la visión liberal que exige un espacio intangibilidad. En esto nos diferenciamos, por ejemplo, del sistema constitucional colombiano ${ }^{42}$ que muestra una mayor tendencia a legitimar la intervención estatal sobre los contratos e incluso a que se intervenga directamente para regular su contenido frente a situaciones injustas ${ }^{43}$. No pretendemos juzgar

40 FULLER, Lon: La moral del derecho. Trillas, México, 1967. (Traducción de Francisco Navarro). p. 64.

41 FIORE, cit., pp. 28-29.

42 Cabe resaltar que, la Constitución colombiana no reconoce de modo directo la libertad de contratar, sino que su protección es derivada de la libertad de empresa, libre iniciativa privada, libre desarrollo de la personalidad y función social de la propiedad (Sentencias C 288-2012 y SU 157-1996). En ese sentido, reconoce que el derecho a la autonomía privada no es un poder atribuido ex negotium, sino que emana de la ley y de la Constitución y, en esa medida tiene un carácter instrumental, pues "no se concibe como un simple poder subjetivo de autorregulación de los intereses privados, sino como el medio efectivo para los fines correctores del Estado social, a través del mejoramiento de la dinámica propia del mercado" (Sentencias C 186-2001 y T 423-2003).

43 Puede revisarse las causas de la Corte Constitucional colombiana relacionadas con la negativa de contratar de una empresa que tenía el monopolio de un producto (Sentencia T 375-1997); o la cancelación definitiva de un contrato de cuenta corriente a una empresa que podría estar vinculada a narcotráfico (SU 157-1999), o los mandatos de la Corte para cesar las acciones de cobranza, prohibir el cumplimiento anticipado y de renegociar los contratos de mutuo celebrados bajo coacción por personas secuestradas (Sentencia T 520-2003, T 212-2005, T 312-2010, T 246-2014), o la sentencia que impuso a un banco la exigencia de darle un tratamiento contractual especial a un enfermo de sida 
los criterios de ese tribunal extranjero, sino resaltar que un proceder similar no sería aplicable en el Perú, pues nuestro texto fundamental nos ata a respetar los términos pactados en los contratos y dispone que los eventuales cuestionamientos contra las injusticias contractuales se realicen solo ante tribunales arbitrales o, su alter ego, los jueces civiles, quienes aplicarán las normas constitucionales y las instituciones civiles que, desde hace siglos, existen y han sido diseñadas para proteger a las partes frente a las injusticias contractuales. Ese es nuestro diseño constitucional.

\subsection{Encuadre comparado de la convivencia de visiones.}

Teniendo en cuenta los elementos anteriores podemos evaluar las hipótesis que mencionamos al inicio de estas líneas. Así, debido a las circunstancias que vivimos es innegable que existe un interés social que justificaría cierta intervención legislativa en los contratos de algunos sectores.

La nueva ley podrá tener efectos inmediatos sobre las consecuencias actuales de los contratos previos en el sector educación, arrendamiento, o mutuos bancarios, sin embargo, debe tenerse cuidado para que el nivel de esa intervención no sea inconstitucional. Eso ocurriría si, por ejemplo, la nueva ley realiza una fijación de precios en los contratos, traslada todos los costos del contrato a solo una de las partes o, en fin, toma alguna medida similar que elimina el interés que justificaba la contratación misma, vaciando de contenido la libertad de contratación. Esa nueva ley sería legítima en cuanto a su aplicación en el tiempo, pero sería ilegítima en cuanto a su contenido.

Para seguir con el ejemplo comparado de Colombia debemos hacer referencia a la distinción que hace su jurisprudencia entre retroactividad y retrospectividad de las nuevas leyes sobre contratos previos (Sentencia C 147/1997). Lo primero supondría alterar situaciones o consecuencias

e incluso ordenó la refinanciación del contrato, modificación que, además, debía ser aprobada por la Corte (Sentencia T 170-2005). MORALES HUERTAS, Margarita: "Constitución y límites a la autonomía privada". En: Neme Villareal, Martha Lucia (coordinadora): Autonomía privada. Perspectivas de derecho contemporáneo. Universidad Externado de Colombia, Bogotá, 2018. pp. 195 y ss. MUÑOZ LAVERDE, Sergio: "El postulado de autonomía privada y sus límites frente al constitucionalismo colombiano contemporáneo". En: AAVV Homenaje Fernando de Trazegnies Granda. Tomo II, Fondo Editorial de la PUCP. Lima, 2009. p. 287. CALDERÓN VILLEGAS, Juan Jacobo: La constitucionalización del derecho privado. La verdadera historia del impacto constitucional en Colombia. Universidad de los Andes. Bogotá. 2013. pp. y ss. 
jurídicas consumadas antes de las nuevas leyes, lo que se encontraría proscrito por el sistema constitucional (Sentencia 549/93) y lo segundo una intervención inmediata para lo que viene en los contratos después de la sanción de la ley. Esta distinción ha permitido considerar como constitucionales aquellas nuevas leyes que, por ejemplo, alteraban ciertos beneficios aplicables a los contratos laborales previamente suscritos, pero sin modificar los beneficios devengados previamente (Sentencia C 177/2005); o un nuevo régimen que prohibía en lo sucesivo que los bancos apliquen penalidades por pagos anticipados de créditos, aunque tales penalidades hayan sido pactadas en contratos previos (Sentencia C 313/2013).

Hinestrosa refiere que en el derecho colombiano y comparado hay un cambio de visión que exige la intervención del Estado en los contratos, pero aún en forma sedimentaria, de manera excepcional cuando concurran razones de orden público que exigen anteponer la justicia contractual sobre su intangibilidad ${ }^{44}$. $\mathrm{Y}$ es que señala: "Razones de necesidad suprema, de apremio de prestar atención a circunstancias extraordinarias y resolver equitativamente urgencias inaplazables fueron llevando a los distintos ordenamientos, con gran dificultad a aceptar excepcionalmente intervenciones imperativas del legislador en términos de vigencia inmediata universal de la nueva ley, esto es, de su eficacia por encima de la relación contractual o, mejor, a contrario de ella ${ }^{45 "}$.

También es pertinente recurrir a la jurisprudencia constitucional chilena que cambió sus iniciales criterios liberales que proclamaban la intangibilidad de los contratos, la aplicación de la teoría de los derechos adquiridos, que permitían seguir aplicando a los contratos la legislación vigente al momento de su celebración (Rol 207-19956). Para eso, debe

44 HINESTROSA, Fernando: Tratado de las obligaciones II. Volumen I. Universidad Externado de Colombia, Bogotá, 2015. pp. 185-191.

45 Ibídem, pp. 365-366

46 Ese fallo el TC chileno fijó el siguiente criterio: "Que fue precisamente el hecho de celebrar el contrato de adquisición de las referidas acciones preferidas lo que determinó indefectiblemente la incorporación al patrimonio de los accionistas de los derechos establecidos en la legislación vigente a la época de su adquisición. Fue efectivamente aquel hecho, la circunstancia fáctica con aptitud suficiente para traer como consecuencia la incorporación inmediata de un derecho de carácter patrimonial, protegido por la garantía [de la propiedad]... y, por lo tanto, estableció una limitación a las atribuciones del legislador en el sentido de carecer de facultades para alterarlo, menoscabarlo o anularlo por una norma posterior" (fd. 63, ver también fd. 67). A partir de ahí, se señala 
tenerse en cuenta que en ese país la Constitución Política no reconoce de modo directo la intangibilidad de los contratos, sino que, a partir del reconocimiento de la propiedad (art. 19, numeral 24 de su Constitución) deriva la protección de bienes incorporales (derechos de crédito) que surgen de los contratos.

El 2006 llegó al TC de Chile las causas promovidas por Empresa Eléctrica Panguipulli S.A. y Empresa Eléctrica Puyehue S.A. (Roles $\mathrm{N}^{\circ}$ 505-06 y 506-06) quienes alegaron lesión de sus derechos a la propiedad y libertad de contratar debido a que una nueva ley fijaba otros montos de peajes por uso de infraestructura eléctrica de transmisión, lo que, a su juicio, constituía una ley retroactiva que afectaba sus contratos suscritos años antes y que fijaban montos menores. Ese TC reconoció que los contratos contenían derechos incorpóreos a usar la infraestructura a cambio de peajes específicos, sin embargo, precisó que tales derechos, en cuanto derecho de propiedad, eran pasibles de las limitaciones que exija el interés social. Remata el argumento precisando que, el texto constitucional no precisaba que los bienes incorpóreos que nazcan de los contratos no puedan cumplir la función social que se asigna a la propiedad, lo que indicaría que no existe una intangibilidad absoluta de los contratos frente a nuevas leyes; sin embargo, señala, el hecho que se trate derechos nacidos de acuerdos privados y no de las leyes, hace más difícil justificar una limitación de ellos por razones de interés social (fds. 16-19 y también González Castillo 2007: 351 y ss y Romero Guzmán, 2007: 19 y ss).

Usando esos criterios interpretativos chilenos, colombianos y nuestra propuesta, podríamos arribar estandarizar el análisis aplicable a la relación de los contratos frente a las nuevas leyes:

- Primero, debería verificarse que la nueva ley no sea retroactiva, lo que ocurrirá si solo incide sobre las consecuencias actuales de los contratos previos.

que hubo un reconocimiento de la teoría de los derechos adquiridos en los contratos, aunque desde siempre han existido ciertas críticas. Cfr.

CHANÁ CARIOLA, Julio; EVANS DE LA CUADRA, Enrique; LECAROS ZEGERS, Raúl; VERGARA BLANCO, Alejandro; ÁLVAREZ ZENTENO, Rodrigo y EVANS ESPIÑEIRA, Eugenio: "Estudio crítico de las doctrinas jurídicas contenidas en la sentencia del Tribunal Constitucional de 10 de febrero de 1995". En: Revista chilena de derecho, Vol. 22, $\mathrm{N}^{\circ}$ 33, Santiago de Chile, 1995. pp. 584-586. LÓPEZ SANTA MARÍA, Jorge: Los contratos. Parte general. Tomo I. $2^{\mathrm{a}}$ edición. Editorial Jurídica de Chile, Santiago de Chile, 1998. pp. 278-286. 
- Segundo, debe detectarse que exista un motivo de interés público que justifique la intervención inmediata sobre las consecuencias de los contratos (lo que será muy difícil en los acuerdos entre privados y menos complicado en los contratos con el Estado).

- Tercero, debe evaluarse si la intervención es legítima, ya sea porque no afecta otros valores constitucionales, o porque no es excesiva al punto de vaciar de contenido al interés en el contrato mismo ${ }^{47}$.

Si bien nos hemos alejado del objeto de estas líneas, era preciso referirnos a los límites constitucionales a los que debe sujetarse las nuevas intervenciones legislativas sobre las consecuencias de contratos previamente suscritos. Sin embargo, el detalle de tales límites es una cuestión que se aleja del tema que nos convoca.

Retomando el hilo conductor, debemos señalar que tal como prevé el artículo 62 de la Constitución peruana, las controversias que se generen por la magnitud de la intervención de la nueva ley sobre las partes del contrato podrán discutirse en la vía judicial o arbitral que hubieran pactado ya sea para discutir supuestos netamente contractuales de fuerza mayor, excesiva onerosidad de la prestación, imposibilidad sobrevenida, extinción del contrato, o incluso para pedirle al juez civil o al tribunal arbitral (STC 0142-2011-AA, fds. 22-26) que mantenga inalterables los términos del acuerdo y que inapliquen la ley al caso concreto en vía de control difuso de constitucionalidad de tal ley. Mientras que los reclamos directos contra el legislador o la autoridad estatal que aplique la nueva e inconstitucional ley podrán hacerse en la vía judicial de amparo o en sede contenciosoadministrativa, según corresponda.

En todo caso, se debe tener siempre presente que la nueva visión de los contratos no es una carta blanca al legislador, sino que exige una adecuada

47 Sobre esto último, la jurisprudencia constitucional chilena tiene un sostenido desarrollo en donde precisa que las nuevas leyes pueden limitar o regular la propiedad (y con ello, la libertad de contratar) siempre que tal incidencia no llegue a un punto en donde se elimina o expropia esos derechos. Se precisa así que la regulación inevitablemente afectará algún atributo, facultad o privilegio, sin embargo, no todos ellos están protegidos, pues de lo contrario la intervención para concretar la función social de los bienes se convertiría en letra muerta, el asunto es que esa medida deje subsistente las facultades esenciales que se tenían (Roles $\mathrm{N}^{\circ} 229-12$, fds. 8-9 y 24, $\mathrm{N}^{\circ} 245-96$, fd. 22 y $\mathrm{N}^{\circ} 505-06$ y 506-06, fd. 6 y, en doctrina MATUTE, cit., pp. 114-174 y ALDUNATE, cit., pp. 285-303). Estos criterios bien pueden ser trasladados a nuestro país en virtud de nuestra jurisprudencia constitucional sobre razonabilidad y expropiación regulatoria (VELÁSQUEZ, cit., pp. 46 y ss y PASQUEL, cit., pp. 114 y ss). 
técnica legislativa para intervenir de manera legítima en las consecuencias de los contratos previos.

\subsection{Unidad y concordancia práctica de las normas constitucionales.}

En estas líneas no buscamos favorecer a la socialización de los contratos que habiliten a necesarias y legítimas intervenciones de leyes posteriores sobre ellos para corregir injusticias inadmisibles bajo nuestro sistema de valores constitucionales. Tampoco se trata de hacer prevalecer la filosofía liberal que se inclina a favor de la máxima protección de la libertad de contratación frente a toda medida estatal adoptada con posterioridad a la celebración del acuerdo.

No hay espacio para negar o para eliminar alguna de esas dos opciones porque ambas encuentran sustento constitucional, por lo que estamos forzados a encontrar una fórmula interpretativa que permita que ambas tendencias convivan bajo un único sistema. Para lograr eso será necesario recurrir a la jurisprudencia del TC y, en especial, a los principios de unidad y concordancia práctica que resumió Hesse $\mathrm{e}^{48}$ como cánones de interpretación constitucional. El primero exige interpretar las normas constitucionales "como un 'todo' armónico y sistemático, a partir del cual se organiza el sistema jurídico en su conjunto" y el segundo exige resolver toda aparente tensión entre las disposiciones constitucionales "optimizando" su interpretación, es decir, sin "sacrificar" ninguno de ellos, pues cada uno protege a su manera distintas manifestaciones del principio-derecho de dignidad humana (STC 5854-2015-AA, fd. 12).

Estamos convencidos de que es posible una convivencia armónica entre la visión socializadora de los contratos y la visión liberal del mismo, cada uno dentro de su espacio propio. De modo que, no sería necesario sacrificar ninguna disposición constitucional en favor de una u otras norma o interpretación.

En efecto, si bien el artículo 62 de la Constitución se inspiró en las ideas de Torres y Torres Lara, el texto normativo no llegó a representar totalmente sus intenciones de hacer inalterable "todos" los elementos del contrato, sino que solo alcanzó para hacer inalterable parte del fenómeno contractual, solo los "términos del contrato".

Así las cosas, el artículo 103 de la Constitución (y desde tiempo atrás, el artículo III del Título Preliminar del Código Civil) abre las puertas al

48 HESSE, Konrad: Escritos de derecho constitucional. Centro de Estudios Constitucionales. Madrid, 2012. (Traducción de Pedro Cruz Villalón). pp. 67-68. 
legislador para que pueda intervenir con nuevas leyes sobre los contratos. Pero no puede hacerlo sobre el contenido ya pactado, sino que la eficacia inmediata de esas nuevas leyes recaerá sólo sobre las consecuencias actuales que despliegan los contratos ya existentes. No se trata de poca cosa, pues la incidencia legislativa sobre las consecuencias de los contratos podría generar la extinción (por ineficacia) de estos, o forzar a las partes a renegociar sus acuerdos para seguir beneficiándose de ellos.

Desde luego, los cambios legislativos que afecten las consecuencias de los contratos podrán dar lugar a controversias ante jueces o árbitros. Allí no solo podrá discutirse la legitimidad o conveniencia de continuar o terminar con el contrato. Incluso esa controversia podría dirigirse a discutir los excesos y arbitrariedades de la nueva ley sobre los contratos. Ambas posturas tendrán iguales oportunidades de cuestionar la existencia de contratos injustos o el dictado de leyes injustas contra sus contratos. De hecho, el TC ha resueltos casos en donde se cuestionaban tanto los excesos o injusticias de contratos específicos, como casos en donde lo que se impugnaba eran nuevas leyes o normas que afectaban la libertad de contratar.

Nuestro TC ha actuado tanto como controlador de contratos injustos y también como guardián de leyes injustas contra contratos.

Con esto aclarado, creemos que hemos acreditado que nuestra propuesta encuentra respaldo suficiente para ser aceptada. Defendemos que el artículo 103 de la Constitución permite que el legislador intervenga sobre unos aspectos del contrato, sin afectar, ni reducir, las garantías que textualmente consagra el artículo 62 de la Constitución a favor de los contratos. Asimismo, nuestra propuesta permite que quienes se crean afectados en su libertad de contratar por las nuevas leyes, acudan a los jueces o árbitros para pedir tutela contra la supuesta medida legislativa arbitraria, o que acudan a esas instancias las partes que consideren que necesitan tutela contra las injusticias del contrato que la nueva ley buscaría combatir.

\section{CONCLUSIONES.}

En estas líneas hemos encontrado tres razones fundamentales por las que no se puede seguir sosteniendo un régimen de intangibilidad de los contratos o de derechos adquiridos frente a nuevas leyes que puedan alterarlos. 
La primera razón es de derecho positivo, pues los textos de los artículos 62 y 103 de la Constitución y su jurisprudencia permiten entender que debe establecerse una diferenciación entre los términos contractuales y a sus consecuencias. La primera exige que los acuerdos no sean modificados por nuevas leyes, y los segundos prevé que éstas sí puedan incidir, condicionar, o alterar de forma inmediata las consecuencias actuales de contratos previos. Tal incidencia puede generar supuestos de imprevisibilidad en los contratos o incluso de terminación, que solo pueden ser resueltos en la vía judicial o arbitral, salvo acuerdo entre las partes.

La segunda razón es de corte material o valorativo, pues los principios liberales que inspiraron la libertad de contratar visto como intangibilidad de los contratos han variado mucho en la actualidad peruana y francesa donde se originó, de modo que la falta de paridad entre las partes y otras circunstancias excepcionales de interés público, exigen filtrar una visión estatal más interventora en los contratos mediante nuevas leyes.

La tercera razón es derecho constitucional comparado, pues los sistemas latinoamericanos con cierta apertura a las nociones liberales de la autonomía privada, como en Chile, Colombia y Perú, han podido conjugar aquellas visiones junto con la visión social o interventora de esas libertades en supuestos de necesidad social. Si bien recurren a elementos o criterios diferentes para lograr esa convivencia, es indicativo que ninguno renuncie a una visión en favor de otro.

No se debe olvidar que la posibilidad de intervenir en los contratos mediante nuevas leyes no supone tampoco una carta blanca al legislativo, sino que puede someterse a un análisis estandarizado en donde debe verificarse la irretroactividad de la nueva ley, que exista un real motivo de interés público que justifique la intervención y que dicha intervención sea de dimensiones proporcionales o razonables.

Entendida correctamente la libertad de contratar, considerará que el dictado de nuevas leyes que toman medidas para afrontar la crisis generada por la pandemia encontrará, sin duda, tienen justificación en el interés público. Pero para ser legítimas, la libertad de contratar además exigirá, que esas leyes incidan solo sobre las consecuencias actuales de los contratos y de una manera razonable, que no vacíe de contenido a la posición de la otra parte de los contratos. 


\section{BIBLIOGRAFÍA.}

ALBALADEJO, Manuel: Derecho civil. TomoI. 15 a edición. Bosch. Barcelona, 2012.

ALDUNATE, Eduardo: "Limitación y expropiación: Scilla y Caribdis de la dogmática constitucional de la propiedad". En: Revista Chilena de Derecho, Vol. 33, № 2, 2006.

BORDA, Guillermo: Manual de derecho civil. Parte general. $18^{\text {a }}$ edición. Editorial Perrot, Buenos Aires, 1996.

CALDERÓN VILLEGAS, Juan Jacobo: La constitucionalización del derecho privado. La verdadera historia del impacto constitucional en Colombia. Universidad de los Andes, Bogotá, 2013.

CÁRDENAS QUIRÓS, Carlos: "Autonomía privada, contrato y Constitución”. En: Bullard, Alfredo y Fernández, Gastón (editores): Derecho civil patrimonial. Pontifica Universidad Católica del Perú, Lima, 1997.

CÁRDENAS QUIRÓS, Carlos: "La supuesta santidad de los contratos y el artículo 62 de la Constitución Política del Perú". En: Gaceta Jurídica, Tomo 73-B, Lima, 1999.

CARRIÓ, Genaro: Algunas palabras sobre las palabras de la ley. AbeledoPerrot, Buenos Aires, 1971.

CHANÁ CARIOLA, Julio; EVANS DE LA CUADRA, Enrique; LECAROS ZEGERS, Raúl; VERGARA BLANCO, Alejandro; ÁLVAREZ ZENTENO, Rodrigo y EVANS ESPIÑEIRA, Eugenio: "Estudio crítico de las doctrinas jurídicas contenidas en la sentencia del Tribunal Constitucional de 10 de febrero de 1995". En: Revista chilena de derecho, Vol. 22, № 33, 1995.

CROSS, Rupert y HARRIS, J. W.: El precedente en el derecho inglés. Traducción de Angélica Pulido. Marcial Pons, Madrid, 2012.

CONTHE, Manuel: Pensar con arte. Biblioteca Nueva, Madrid, 2014.

DE CASTRO Y BRAVO, Federico: Derecho civil de España. Tomo I. Reimpresión del 2008. Thomson-Civitas, Madrid, 1984. 
DE LA PUENTE Y LAVALLE, Manuel: "La libertad de contratar". En: Themis-Revista de Derecho, N 33, 1996.

DIEZ-PICAZO GIMÉNEZ, Luis María: La derogación de las leyes. Civitas, Madrid, 1990.

DIEZ PICAZO P. Luis y GULLÓN, Antonio: Sistema de derecho civil. Tomo I. 13ª edición. Tecnos, Madrid, 2019.

DÍAZ AZNARTE, María Teresa: Teoría general de sucesión de normas en el tiempo. Tirant lo Blanch, Valencia, 2002.

FIORE, Pascuale: De la irretroactividad e interpretación de las leyes. Traducción de Enrique Agulera de Paz. 4ª edición. Reus, Zaragoza, 2009.

FULLER, Lon: La moral del derecho. Traducción de Francisco Navarro. Trillas, México, 1967.

GONZÁLEZ CASTILLO, Joel: "El derecho de propiedad y la intangibilidad de los contratos en la jurisprudencia de los requerimientos de inaplicabilidad”. En Revista chilena de derecho, Vol. 34, N 2, 2007.

GOODHART, Arthur: "Determining the Ratio Decidendi of a Case". En: Yale Law Journal, Nº 40, 1930.

GOODHART, Arthur: "The Ratio Decidendi of a Case". En: Modern Law Review. $\mathrm{N}^{\circ} 22,1959$.

GUTIÉRREZ CAMACHO, Walter: "Adiós a la santidad de los contratos". En: Gaceta Jurídica, Tomo 73-B, 1999.

HATTENHAUER, Hans: Conceptos fundamentales de derecho civil. Traducción de Gonzalo Hernández. Ariel, Barcelona, 1987.

HESSE, Konrad: Escritos de derecho constitucional. Traducción de Pedro Cruz Villalón. Centro de Estudios Constitucionales, Madrid, 2012.

HINESTROSA, Fernando: "Función, límites y cargas de la autonomía privada". En: Revista de Derecho Privado, $\mathrm{N}^{\circ} 26$, Universidad Externado de Colombia, 2014.

HINESTROSA, Fernando: Tratado de las obligaciones. Tomo II, Vol. I. Universidad Externado de Colombia, Bogotá, 2015. 
KEMELMAJER DE CARLUCCI, Aída: La aplicación del Código Civil y Comercial a las relaciones y situaciones jurídicas existentes. RubinzalCulzoni, Buenos Aires, 2015.

LANDA ARROYO, César: "La constitucionalización del derecho civil: el derecho fundamental a la libertad contractual, sus alcances y sus límites". En: Themis-Revista de Derecho, № 66, 2014.

LARROUMET, Christian: Teoría general del contrato. Volumen I. Traducción de Jorge Guerrero. Temis, Bogotá, 1999.

LAURENT, Francois: Principios de derecho civil francés. Tomo XVI. El texto original francés data de 1860. Tribunal Superior de Justicia del Distrito Federal, México D.F., 2009.

LEÓN HILARIO, Leysser: "COVID-19, crisis sanitaria y retos del Derecho Civil. Entre la fuerza vinculante y la adecuación de los pactos contractuales". En: entrevista publicada en Gaceta Civil \& Procesal Civil, $\mathrm{N}^{\circ} 82,2020$.

LÓPEZ SANTA MARÍA, Jorge (1998). Los contratos. Parte general. Tomo I. $2^{\text {a }}$ edición. Editorial Jurídica de Chile, Santiago1998.

MATUTE, Claudio: Expropiaciones regulatorias. Aplicabilidad al caso chileno. Thomson-Reuters, Santiago, 2014.

MAZEAUD, Henry; MAZEAUD, León y MAZEAUD, Jean: Lecciones de derecho civil. Parte Primera, Tomo I. Traducción de Luis Alcala-Zamora. EJEA, Buenos Aires, 1959.

MOISSET DE ESPANES, Luis. Irretroactividad de la ley y el nuevo art. 3 del Código Civil. Universidad Nacional de Córdova, Córdova, 1976.

MORALES HUERTAS, Margarita: "Constitución y límites a la autonomía privada". En: Neme Villareal, Martha Lucia (coordinadora): Autonomía privada. Perspectivas de derecho contemporáneo. Universidad Externado de Colombia, Bogotá, 2018.

MUÑOZ LAVERDE, Sergio: "El postulado de autonomía privada y sus límites frente al constitucionalismo colombiano contemporáneo". En: AAVV, Homenaje Fernando de Trazegnies Granda. Tomo II. Fondo Editorial de la PUCP, Lima, 2009.

NINAMANCCO CÓRDOVA, Fort: La invalidez y la ineficacia del negocio jurídico. Gaceta Jurídica, Lima, 2014. 
PASQUEL, Enrique: "Tomando la propiedad en serio: las expropiaciones regulatorias o indirectas". En: Ius et Veritas, N 31, 2005.

POZO SÁNCHEZ, Julio: Summa Civil. Nomos \& Tesis, Lima, 2019.

RIVERA, Julio César: Instituciones de derecho civil. Parte general. Tomo I. Lexis-Nexis, Buenos Aires, 2004.

ROMERO GUZMÁN, Juan José: "Cambio en la regulación eléctrica y estabilidad de los contratos: ¿Cuándo una limitación se transforma en privación? ¿Cuándo compensar?”. En: Fermandois Vöhringer, Arturo (editor): Sentencias Destacadas 2007. Libertad y Desarrollo, Santiago, 2008.

ROPPO, Vicenzo: El contrato. Traducción de Eugenia Ariano Deho. Gaceta Jurídica, Lima, 2009.

RUBIO CORREA, Marcial: Estudio de la Constitución Política de 1993. Tomo III. Pontifica Universidad Católica del Perú, Lima, 1999.

SAAVEDRA VELAZCO, Renzo: Análisis económico y comparado del derecho privado. Fogueras, Lima, 2016.

SCHAUER, Frederick: Las reglas en juego. Un examen filosófico de la toma de decisiones basada en reglas en el derecho y en la vida cotidiana. Traducción de Claudina Orunesu y Jorge L. Rodríguez. Marcial Pons, Madrid, 2004.

VELÁSQUEZ, Raffo: "Expropiación indirecta. Justificación, regímenes, casos, criterios y usos", En: Ius et veritas, $\mathrm{N}^{\circ}$ 46, 2013.

TOULMIN, Stephen: Los usos de la argumentación. Traducción de María Morrás y Victoria Pineda. Editorial Península, Barcelona, 2007.

ZIMMERMANN, Reinhard y WHITTAKER, Simon: Good faith in european contract law. University Press, Cambridge, 2000. 